\title{
Spatial and temporal synchronization of water and energy systems: Towards a single integrated optimization model for long-term resource planning
}

\author{
Zarrar Khan ${ }^{\mathrm{a}, \mathrm{d}, *}$, Pedro Linares ${ }^{\mathrm{a}}$, Martine Rutten ${ }^{\mathrm{b}}$, Simon Parkinson ${ }^{\mathrm{c}, \mathrm{d}}$, Nils Johnson ${ }^{\mathrm{d}}$, Javier \\ García-González ${ }^{a}$ \\ ${ }^{a}$ Instituto de Investigación Tecnológica, Universidad Pontificia Comillas, Alberto Aguilera 23, 28015 Madrid \\ ${ }^{b}$ Water Management, Civil Engineering $\&$ Geosciences, TU Delft, PO Box 5048, 2600 GA Delft, Netherlands \\ ${ }^{c}$ Institute for Integrated Energy Systems, University of Victoria, Canada \\ ${ }^{d}$ International Institute for Applied Systems Analysis (IIASA),Schlossplatz 1,A-2361, Laxenburg, Austria
}

\begin{abstract}
Predictions show that pressure on already limited water and energy resources is expected to increase in many parts of the world as a result of growing populations, rapid urbanization, increasing pollution and climate change impacts. With water and energy playing a critical role in socio-economic development, ensuring resource security is a top policy concern. However, achieving this efficiently requires taking into account the various links between the two sectors through their joint management. Feedback between the water and energy sectors exists across system life-cycles and links the resources both spatially and temporally. Tracking the impacts of policies made in one sector on the other can thus be complicated and several 'nexus' methodologies have been developed to try and address these issues. However, the different physical, temporal and spatial characteristics of the water and energy systems present several hurdles in analyzing the two resources simultaneously. This paper overcomes many of these problems with a new, fully coupled waterenergy optimization model. Based on a review of contemporary literature, the model develops an original methodology to hard-link the two systems in detail across spatial and temporal scales, as well as between individual system processes throughout the life-cycle of each resource. In addition, the model also tracks changes in water quality through each process, allowing for detailed accounting of the energy needs for water treatment. The methodology proposed in this paper can be used to investigate various cross-sectoral issues and policies such as: water availability and temperature impacts on power plant cooling; emission constraint and biofuel expansion planning impacts on water resources; and the implications of water infrastructure expansion on the energy system. The capabilities of the coupled model are investigated in an example case study for Spain. An integrated approach is shown to have several benefits including lower total costs, better resource efficiency and improved robustness for a wide range of variations in several uncertain parameters. Coupled water-energy planning thus provides a critical opportunity to improve resource security and prevent inefficient decisions which could exacerbate problems even further.
\end{abstract}

Keywords: Water-energy nexus, integrated planning, optimization modeling

\section{Introduction}

In several regions of the world such as California, the Mediterranean region, China, India and the Middle East, concerns about future energy and water security are increasing due to various factors including, growing populations, increasing pollution, overuse of non-renewable resources and the impacts of climate change. Interdependencies between the two sectors make the situation even more urgent and several international organizations have conducted various water-energy nexus studies [1, 2, 3, 4, 5, 6, 7, leading to a better

\footnotetext{
* Corresponding authors

Email addresses: Zarrar.Khan@iit.comillas.es (Zarrar Khan), Pedro.Linares@iit.comillas.es (Pedro Linares)
} 
understanding of the inter-relationships between the two sectors. Energy is used for water extraction, pumping, desalination, purification and distribution while water is used in energy extraction and mining, hydro-power generation, power plant cooling and to irrigate bio-energy crops.

Several energy production alternatives such as concentrated solar power (CSP), bio-fuels, hydraulic fracking for shale gas, coal-to-liquid plants, nuclear power and carbon capture and storage (CCS) can be more water intensive than their traditional counterparts and will increase water stress if not planned strategically [8]. Expansion of water infrastructure to ensure water security can also have important impacts on the energy sector. For example, a study from Texas 9 ] estimates desalination and long-haul transfer to be between nine to twenty three times more energy-intensive per unit of water than conventional treatment of local surface water, while in the Middle East, ignoring the additional feedback of electricity demand from future water system needs has been shown to lead to an almost $40 \%$ underestimation of future electricity needs for 2050 [10.

Such nexus impacts are causing concern and call for more holistic, integrated assessments, to better evaluate the robustness of different policies across both sectors. Taking the links between the sectors into consideration gives rise to new questions that nexus models must answer: What will be the impacts of particular energy technologies on water resources and how will these impacts vary spatially? How will future water quality, quantity and temperature changes impact existing energy technology efficiencies? How much additional energy will be consumed by additional water extraction infrastructure and what alternatives are available? How will these impacts play out with seasonal changes in demands and resource availability? What role can demand side management play in cross-sectoral efficiency?

In response, many attempts have been made to incorporate elements of the water-energy nexus in several modeling efforts. A review of some of these studies, discussed in more detail in Section 2 reveals various hurdles that have prevented the development of the kind of tool that can reliably answer the nexus questions asked in the previous paragraph. These hurdles include: difficulties in identifying relevant water-energy links; managing the trade-offs between increasing model details and solution efficiency; capturing life-cycle crosssector feedback; synchronization of spatial and temporal scales; differences in the physical characteristics of water and energy; sparse data; and large uncertainties.

This paper presents the SPATNEX-WE (SPAtial and Temporal NEXus - Water Energy) model which addresses several of these issues. The model is a hard-linked partial equilibrium linear optimization model which tracks energy flows throughout the life-cycle of the water system and both water withdrawal and water consumption 1 throughout the life-cycle of the energy system. The model represents both water and energy systems in equal detail across spatial and temporal scales as well as through individual processes, allowing users to pinpoint where, when and in which processes changes occur as a result of policy, socio-economic or climatic changes. In addition to volumetric flows, the model also tracks changes in water quality through each process. Given appropriate data availability, the model can be spatially dis-aggregated to the desired geographical boundaries. Different temporal scales can be used to characterize different processes such as monthly precipitation or varying energy demand levels for weekend or weekdays. Data is aggregated to the finest common spatial and temporal scales across the water and energy sectors. The two sectors are linked based on cross-sector life-cycle resource consumption, water temperature impacts on power plant cooling, a common objective function and via the management of multi-use reservoirs.

After establishing the initial state of existing water and energy capacity and infrastructure, the model is run to give the optimal investment and operation decisions for both resource systems to meet exogenous demands for a chosen year of analysis. The model can also be run in a recursive mode to explore investment pathways, in which investment decisions for each intermittent year are used as the initial state for the subsequent analysis. This paper only discusses the static mode for a single year. More details of running the model are discussed in Section 3 on the methodology.

The integrated methodology developed in this paper can be used to address several 'nexus' issues im-

\footnotetext{
${ }^{1}$ Water withdrawal is defined as the total volume of water extracted from a system, part or all of which may be returned to the system, for example when water is withdrawn for hydropower production and then subsequently returned for further use downstream. Water consumption is defined as the part of water withdrawn which is not returned to system for example during evaporation.
} 
pacting both the water and energy systems. Such issues include: managing increasing constraints on water availability and temperature for power plant cooling; energy implications of expanding water infrastructure such as long distance water transfers or new desalination plants; and the impacts of energy policies such as greenhouse gas emission constraints or biofuel expansion on water security. The results show that an integrated plan considering a coupled water and energy system provides several additional insights into cross-sectoral resource flows through different processes and life-cycle periods. These additional insights provide the opportunity to build a more robust system which is shown to lower costs, improve efficiency and increase the security of supply across a range of variations in several uncertain parameters such as resource demands and precipitation.

Section 2 reviews some of the existing models and summarizes recommendations from various studies. Section 3 discusses the methodology of the SPATNEX-WE model and how it incorporates the recommendations made from the review. Section 4 develops a baseline case study for the country of Spain which is validated by comparing it with historical values and results from other water-energy nexus studies in the region. In Section 5, the capabilities of the model are demonstrated by investigating a hypothetical future scenario. The performance of the model and benefits of integration are explored by comparing several model runs with and without water-energy inter-linkages. Detailed spatial and temporal variations in various parameters as well as the robustness of the solutions are analyzed as part of the outputs. Section 6 discusses the limitations of the model and possibilities for future developments. Finally, conclusions are offered in Section 7

\section{Literature Review}

With rising populations and growing economic activity in many regions of the world, water-energy nexus issues are becoming critical concerns due to increasing pressures on the two resources. The methodology discussed in this paper is designed to provide additional insights for policy makers and equip them with a tool to better address such issues. Examples of nexus issues which planners have to address include: reduced power plant capacities due to diminishing cooling water availability or increasing cooling water temperatures [1] [12] 13] [4; missed opportunities from improved water and energy efficiency improvements [14 [15] 16]; conflicts between different sectors for water use such as hydropower, irrigation, environmental flows and industry [17 [18, [19] 20, 21]; impacts of energy subsidies on groundwater overpumping [22 23]; energy impacts of water extraction 24 [10, 29 25] and treatment 26 27 technologies; water impacts of energy policies such as biofuel expansion 28] 29]; and several examples of regional conflicts for water shared across administrative boundaries and used for multiple purposes [30] [31]. The methodology described in this paper aims to help planners gain a better understanding of such issues by capturing the flows of energy and water across sectors as well as spatial and temporal units.

Integrating water and energy systems requires compromising between the distinct conventional modeling approaches established in the two sectors. The traditional approach to modeling complex and non-linear water system processes has been to use hydrological allocation models such as WEAP 32 to investigate different "what-if" scenarios such as changes in reservoir operation rules, allocation priorities, crop mixes and climate change impacts on both final demands and water availability. Simulation models are not restricted to any particular form of functional relationships unlike optimization models, in which all processes need to be modeled as compatible, often simplified, equations conforming to the chosen optimization algorithms 33 . In water resources, optimization has primarily been used in making allocation priority decisions, often by maximizing the common economic benefits derived from different water withdrawals in Integrated Water Resource Optimization models (IWROM) [34. Other models such as OPTIMA [35] use a hybrid methodology to find pseudo-optimal solutions by combining the power of complex non-linear simulation programming with discrete multi-criteria methodologies on sets of feasible solutions.

In the energy sector, both simulation models (LEAP [36], POLES [37]) and optimization models (MARKAL [38], TIMES [39]) are widely used. Simulation models in energy systems tend towards more aggregated macroeconomic top-down approaches while optimization models tend towards disaggregated technology based bottomup approaches. In bottom-up models, processes are defined from a technical engineering viewpoint while 
top-down models characterize technologies based on the shares of a given input in intermediary consumption, production functions, labor, capital and other parameters 40. Operation and investment planning decisions taking into account the complexities of the water-energy nexus calls for a detailed techno-economic representation compatible across both sectors and lends it self well to a bottom-up, partial equilibrium linear programming approach close in spirit to the TIMES-MARKAL family of models.

Over the past decade several models have been developed to analyze the water and energy systems simultaneously and have been reviewed in Khan et al. 2017 41. The most common approach to integration has been to include water constraints in already existing energy models [42, 43, 44] [45] [46]. In these models, water systems are however under-represented and physical water resources often ignored. Few models [10, 12 , 47, 48, 49] which do include more detailed water systems reveal additional issues related to the disaggregation and synchronization of the two systems across different scales. A few studies focus on more general, broader links in the energy, water and other economic sectors using methodologies like the open source Global Change Assessment Model (GCAM), input-output analysis and life-cycle analysis [50, 51, 52, 53, 54. Other models integrate individual energy and water models in an iterative way using soft-links [48, 55, [56] which is often the most practical starting point for linking models based on different approaches [57. However, soft-linked models do not guarantee convergence to optimal solutions and the differences between the individual model structures and methodologies make it difficult to achieve consistency [58, [59].

In summary, the various links between the water and energy sectors can lead to unforeseen impacts of technology, infrastructure and regulatory decisions made in one sector on the other. In order to understand these potential impacts, nexus models need to be able to track variations in these impacts spatially, temporally and across the life-cycle chains of each sector. A review of several studies showed that key nexus links to include in integrated water-energy analysis are: water consumption by different energy processes, energy consumption by water processes, modeling of multi-purpose reservoirs, tracking of water quality changes and water temperature impacts on power plant efficiency. Additional challenges include the important compromises that need to be made between the detail and complexity of modeling different processes while maintaining compatibility across sectors, time scales and geographical boundaries. Furthermore, the large uncertainties associated with scarce data, future predictions of resource availability and demands coupled with a range of socio-economic pathways and climate change scenarios call for the need of some form of sensitivity analysis to check for robustness of proposed solutions. While existing efforts address some of these issues, a holistic model which captures all of these essential elements together is still needed. This paper develops a methodology which tackles each of these issues together in a single model as presented in the following sections.

\section{Methodology}

The SPATNEX-WE model is designed to address the issues reviewed in Section 2, A balanced model representing both the water and energy sector life-cycle processes is developed with a flexible framework for choosing spatial and temporal scales as well as a multi-component objective function with adjustable weights. The components of the objective function include costs, emissions, water consumption by the energy system and energy consumption by the water system. The preferences for the linked water and energy criterion are to be elicited during a participative stakeholder process involving all affected parties. Depending on the number and types of stakeholders involved the preferences are to be translated into objective function weights using methodologies such as the analytic hierarchy process (AHP), goal-programming or the reference point methodology [4] 60, 61. In this paper the model only considers system costs with all other objective function component weights being 0 . Impacts of varying weights are to be explored in future research.

The program is a partial equilibrium linear-optimization model with a consistent framework across both sectors. Representing the water system in linear equations requires simplification of several hydrological processes, such as the relationship between hydro-power generation and reservoir heads. The spatial and temporal variations of water consumption in the energy sector, energy consumption in the water sector, operation costs, investment costs and emissions are tracked throughout the life-cycle of both resources. Both water quality changes through different processes as well as water temperature impacts on power plant cooling efficiency are also taken into account. 
The model is programmed in GAMS (General Algebraic Modeling System [62]) and can be thought of as consisting of a single model with two hard-linked sub-modules: the energy module and the water module. Subsection 3.1 describes the overall scope of the proposed model. The various links between the two sub-modules are explored in subsection 3.2. Each sub-module is then described in further detail in subsections 3.3 and 3.4 . Detailed equations for the full model are made available in the Supplementary Material.

\subsection{Scope}

The spatial boundaries considered in the model are flexible and can be disaggregated into sub-units according to the needs of the users. The water balance is tracked within each chosen spatial sub-division and water can also be transferred between the sub-units. Each sub-region can have runoff drainage inlets from other regions as well as drainage outlets into other regions or to the coast. Energy extraction and production capacity is identified for each sub-unit, making the two sub-modules spatially compatible. Energy production and investment decisions impact water demands from the energy sector in each unit, while water availability and temperature changes also impact the efficiency and feasibility of operating and investing in different energy technologies in each unit. The existing energy sub-module assumes a single node final energy delivery system without transmission congestion between the spatial sub-units. Both primary and final energy imports and exports are considered from and to this node. A conceptual framework for the model is shown in Figure 1

The temporal scope of the overall model is a single year with further subdivisions in each sub-module. Temporal timescales in water systems can vary from minutes for rainfall and interception evaporation to years for groundwater flow, with a large variation between this range for other processes such as channel flow or sublimation. The water sub-module in the current model is divided into months but can be further distributed over finer time scales if needed. Water storage in the form of reservoirs, rain water harvesting tanks and groundwater aquifers allows management across temporal subdivisions. Given the current limitations of energy storage, and in particular electricity storage, the energy sub-module uses a finer temporal disaggregation with monthly time periods, weekdays and weekends as well as five load-level characterizations from peak to off-peak hours. Both water and energy, demands and production, are then balanced over the common timescale of the month. If finer common temporal divisions are desired then chronological demands for each time period in each spatial unit will be required.

Thus, the model is divided into common spatial and temporal subdivisions over which all input parameters, equations and outputs to be synchronized across the water and energy sectors are then either disaggregated if they exist on a larger scale (e.g. countrywide to river basins or annual data to months) or are aggregated if they exist on a finer scale (e.g. individual plants to river basins or daily data to months).

Processes in the model for both the energy and water systems are modeled for the whole life-cycle of each resource. The energy sub-module considers different forms of primary energy carriers which can be transported and converted to final energy products according to the needs of a variety of different energy service technologies. These technologies serve to satisfy exogenously defined demands for various energy services. Similarly the water sub-module considers exogenous demands for different qualities of water which can be extracted from a range of sources and then processed through different conversion, purification and delivery technologies.

\subsection{Nexus Links Framework}

Based on the conclusions from Section 2 and the findings from the water-energy nexus review paper by Khan et al. 2017 [41, six key links were identified as the most important to model between the water and energy sectors. A conceptual framework for the links is shown in Figure 1 and they are listed below as follows:

i Water quality tracking

ii Multi-purpose reservoirs providing water for electricity, other sectors and storage.

iii Energy consumed by water processes such as desalination or pumping. 
iv Water withdrawn and consumed by energy processes such as bio-energy irrigation or power plant cooling.

$\mathrm{v}$ Water temperature impacts on power plant efficiency.

vi A multiple objective function considering costs, emissions, energy in water and water in energy.

Each of the links is explicitly modeled as constraints in the model. Brief descriptions of these links are provided below with detailed model equations presented in the Supplementary Material.

(i) Water demand for different purposes is in most cases constrained by the quality of the water available. Water for domestic consumption, for example, usually has very stringent quality regulations. The particular quality requirements for each use thus dictates the degree of water purification required and the corresponding energy consumption. Water treatment to different qualities can involve combinations of several different techniques (each with different energy requirements) such as: suspended solids removal; nutrient removal; disinfection with chlorine or ultraviolet radiation; and desalination processes such as reverse osmosis or electrodialysis 63. In order to capture the amount of energy used for water treatment it is thus essential to track the changes in the quality of water flowing through different processes as it is treated to the required state. In this model, all water resources are characterized by a quality indicator such as 'potable', 'saline' or 'waste water'. The degrees of quality can be set by the user based on the local regulations. Each water end-use is similarly characterized by a particular quality. The model thus allows for accurate tracking of the demands for water of a particular quality and the corresponding energy and cost requirements to treat the water to the desired quality. This characteristic of the model adds an additional opportunity for improving efficiency by managing the flows and processing of water quality to different users in time and space. Equation 1 shows the general form of how water quality is tracked through each node. For each spatial sub-unit $s$ and temporal sub-unit $t$, the total sum of the volume of water $W_{i n}$ of different qualities $q$ entering a technology tech, is set to equal the sum of the volume of water leaving the node $W_{\text {out }}$. Each technology is further characterized by equations stipulating what quality of water can enter and what quality of water can leave the technology. Water treatment technologies can change the quality of water for a given cost and energy consumption, while water passing through different end-uses deteriorate in quality. The water model is explained further in Section 3.4 and detailed equations are presented in the Supplementary Material.

$$
\sum_{q} W_{\text {in }}(\text { tech }, q, s, t)=\sum_{q} W_{\text {out }}(\text { tech }, q, s, t)
$$

(ii) Aggregated reservoirs are considered for each basin with maximum and minimum water storage constraints. Hydroelectric energy production is based on an analysis of historical series for hydroelectric energy production, precipitation and outflows. Baseline hydroelectric energy production values are chosen for each month based on mean values from the historical series. Estimates of variations from this baseline hydroelectric production are assumed to be directly proportionate to the variation of precipitation from the historical mean precipitation. Corresponding outflows from reservoirs are then calculated based on the assumption that the potential energy of falling water used to generate hydropower is related to water flows through reservoir turbines given by Equation 2 in which $P$ represents the output power for each spatial sub-unit $s$ and each temporal sub-unit $t, \eta$ is the is the overall efficiency of the hydro plant (i.e. the product of the efficiencies of the turbine and the generator), $\rho$ is the water density, $g$ is the acceleration of gravity, $h$ is the net head and $Q$ is the water flow.

$$
P(s, t)=\eta \times \rho \times g \times h(s) \times Q(s, t)
$$

To convert this to energy we can multiply by the time period considered. In order to incorporate this relationship into a linear model the equation is constructed in the form $y=m x+c$, where $y$ represents the hydropower $P, x$ the discharge $Q, m$ the slope and $c$ the intercept. Comparing this form to equation 2 , the slope $m$ can be expressed by the term $\eta \rho g h$. The constant $c$ is assumed to be 0 meaning that when the discharge is 0 the output power is also 0. For a linear relationship the term $\eta \rho g h$ is assumed to be 
constant and the head $h$ is thus assumed to be fixed. The constant head can be estimated from a linear regression analysis between the historical hydro-electrical energy production and reservoir outflows for each spatial sub-unit. Other methods may also be used, such as the relationship of the head with the reservoir volume and shape of the form $V=k D^{\alpha}$, in which $V$ is the volume, $D$ is the depth or head and $k$ and $\alpha$ are coefficients defining the curvature and slopes of the reservoir shape 64 .

(iii) Energy consumption is tracked through each water process based on the volume of water and any additional parameters, for example the pumping head for groundwater or the net head for long distance transfers. Equation 3 presents an example for the energy needed for groundwater pumping where $E_{g w}$ is equal to the energy consumed by groundwater pumping processes per spatial sub-unit $s$ and temporal sub-unit $t, Q_{g w}$ is the pumped groundwater water volume, $D$ is the groundwater depth, $g$ is the gravity and $\rho$ is the density of water. Other water processes consuming energy include desalination, purification, waste-water treatment and local distribution.

$$
E_{g w}(s, t)=Q_{g w}(s, t) \times D(s) \times g \times \rho \times \eta_{g w}
$$

(iv) Both water withdrawal and water consumption are tracked in energy processes and Equation 4 shows the equation for water consumption. Water withdrawal and consumption parameters per unit of energy produced need to be established to calculate these flows. In Equation 4. $W_{\text {cons }}$ is the volume of water consumed for each energy processing technology tech in each spatial sub-unit $s$ and temporal sub-unit $t, E$ is the energy produced for each technology and $P_{c o n s}$ is the water consumption parameter for each technology giving the water consumption per unit of energy processed.

$$
W_{\text {cons }}(\text { tech }, s, t)=E(\text { tech }, s, t) \times P_{\text {cons }}(\text { tech })
$$

(v) In Figure 1 the link relating water temperature and power plant efficiency is defined as shown in Equation 5 in which the reduction in efficiency is translated into a reduced effective capacity for each generating process, region and time period. The linear correlation of efficiency decrease per unit increment in degrees Celsius has been found to range from $0.01 \%$ up to $0.12 \%$ 65. In the existing model, changes in water temperature are an exogenous input, which need to be entered based on the assumptions and predictions made for the particular climate-change and socio-economic scenario being analyzed. Based on the cooling technology employed by each power plant (Once-through, tower or dry cooling), changes in water temperature result in a corresponding change in plant efficiency. Future developments of the model will add additional endogenous local impacts on water temperature as it passes through different processes supplementing the water temperature change impacts from external events. In Equation $5 P_{\text {eff }}$ is the effective capacity of each energy technology ce, $P_{0}$ is the original capacity, $R$ the relationship coefficient for each technology and power plant cooling technology and $\Delta T$ the change in temperature per spatial sub-unit $s$ and temporal sub-unit $t$.

$$
P_{\text {eff }}(\text { tech })=P_{0}(\text { tech }) \times(1-R(\text { tech }) \times \Delta T(s, t))
$$

(vi) A linear optimization program is used to minimize the objective function which is composed of costs, emissions, energy consumption by the water system and water consumption and withdrawals by the energy system. Costs are composed of operation costs, annualized investment costs, emission costs, export revenues, import costs and non-served resource costs. Equation 6 is a generalization of the multiple objective function. In the water system, paying for energy is not included in the operation costs since the price for energy is not fixed. The costs for energy use in the water system are reflected through energy consumption feedback to the energy system and the sub-subsequent operation costs of processing that energy. Likewise, prices for water or the "water value" in the energy system are endogenous to the model. Investment costs for new infrastructure, power plants and other technologies are based on the estimated lifespan, principal amount per unit of capacity and the interest rate to calculate an amortized annuity. Emission costs are based on carbon emissions from each process per unit of GWh produced and an exogenous carbon price which can be adjusted according to the local regulations. Non-served water and energy resource costs are 
set by final demand sector and also serve as allocating sector priorities. Increasing residential non-served water costs relative to agricultural non-served water will divert water to residential users before agriculture users in scarcity situations. In Equation $6 O_{t o t}$ is the total objective function value, $O_{s u b}$ is the objective function sub-component value for each sub-component $i$ and $W_{s u b}$ is the Objective function sub-component weight.

$$
O_{t o t}=\sum_{i}\left(O_{s u b}(i) \times W_{s u b}(i)\right)
$$

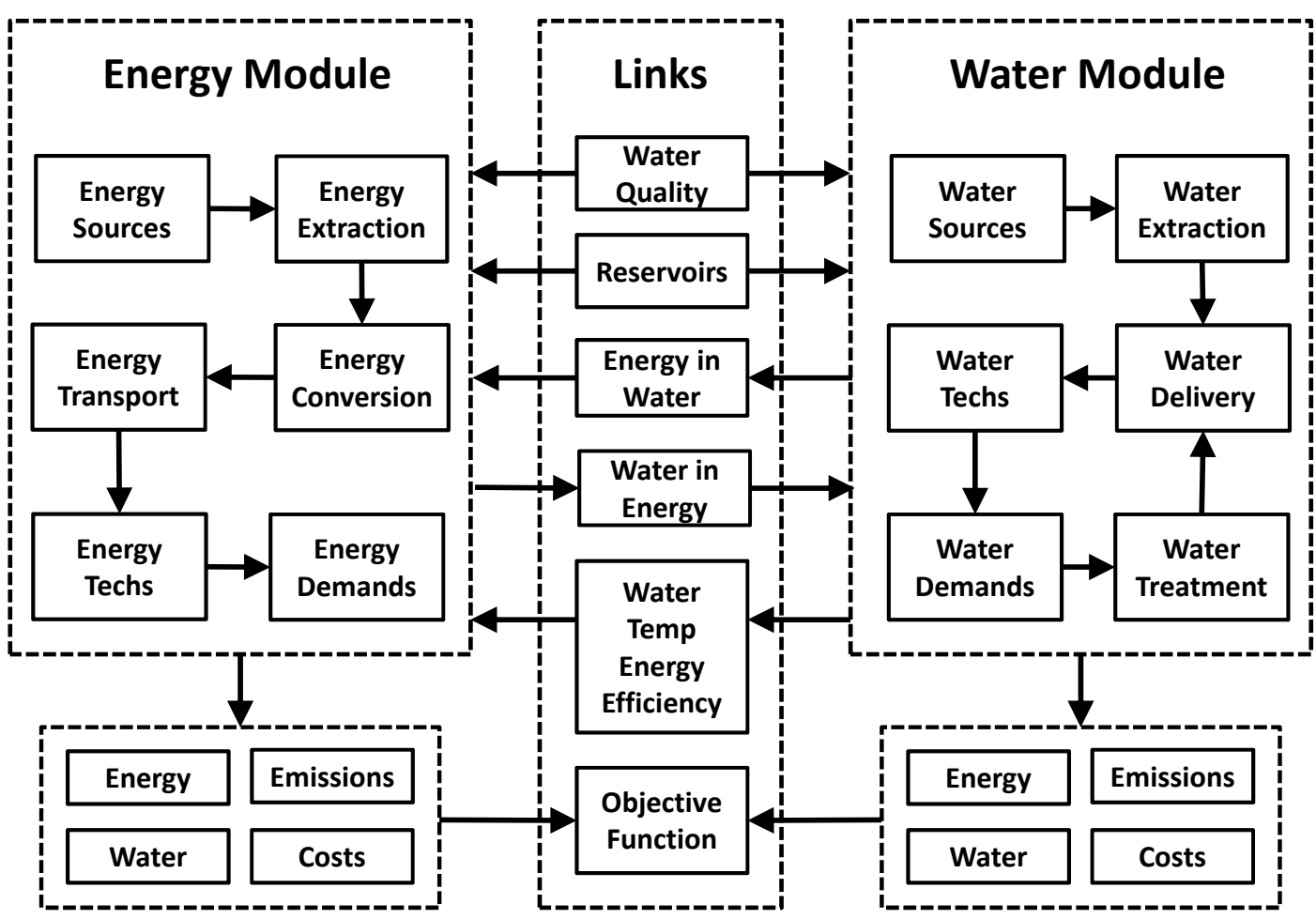

Figure 1: Conceptual model links between the energy and water sub-modules.

\subsection{Energy Model Framework}

The original energy sub-module, was developed at the Institute for Research Technology, Comillas Pontifical University. A brief description of this original model is provided here and a detailed description can be found in the studies by López-Peña et al. [66, 67].

Figure 2 adapted from López-Peña 2014 [66] shows a conceptual diagram of the energy system model. Flows of different energy forms represented by the multi-colored sankey diagram are tracked through four broader energy system process sub-categories represented by the four large vertical rectangles labelled 'Primary Energy', 'Conversion of Energy', 'Transportation of Energy' and 'Demand Sectors'. The flow paths of different colors represent the flow of different forms of energy carriers such as nuclear power, oil, gas, coal or 
electricity. The flow paths enter and leave different smaller boxes, representing particular technologies such as oil refineries, integrated combined cycle coal gasification, open cycle gas turbines or solar photovoltaics. Each technology is located within the larger categories of Primary, Conversion, Transportation or Demand Sector. The existing energy sub-module includes 22 primary energy carriers (e.g. nuclear, coal, gas, solar etc.), 77 conversion energy technologies (e.g. combined cycle coal, gas turbines, co-generation plants, wind etc.), 16 transportation energy technologies (e.g. centralized electricity, gasoline, diesel, distributed heat etc.) and 10 final demand sectors (e.g. industrial mining, residential, services, air transportation etc.). New technologies and sub-sectors can easily be added to the module and will require the corresponding cost and performance parameters. The dotted line around the sankey diagram and sub-category boxes indicates the model spatial boundary, from which energy can be exported or into which energy can be imported.

The demand sector processes are further subdivided into "Energy services" and "Energy Service Supply Technologies" to allow for demand side management. Final demands are allocated for different "Energy Service" processes such as the number of kilometers for inter-urban land transport or heating for residential buildings. The model considers 38 different "Energy Service" categories for the different demand sectors. To satisfy each of these demands the model provides options for 263 different "Energy Service Supply Technologies" (ESST) such as district heating, fluorescent light-bulbs, natural gas boilers or biomass boilers. Each ESST has a different efficiency and cost. The energy sub-module is divided into twelve months, each of which is further divided into working and non-working days. Each day has sub-categories corresponding to five load levels.

As done in several other water-energy nexus models in the literature [42, 43, 44, [45] [46] [68, water constraints were introduced into this energy model in order to study the impacts of water shortages on the energy system in the study by Khan et al. 2016 [69]. However, these models lack a physical water system representation and provide water availability as an exogenous input. This paper advances this previous work by developing a compatible water system sub-module allowing endogenous water resource management and feedback via the established inter-links discussed in subsection 3.2 . 


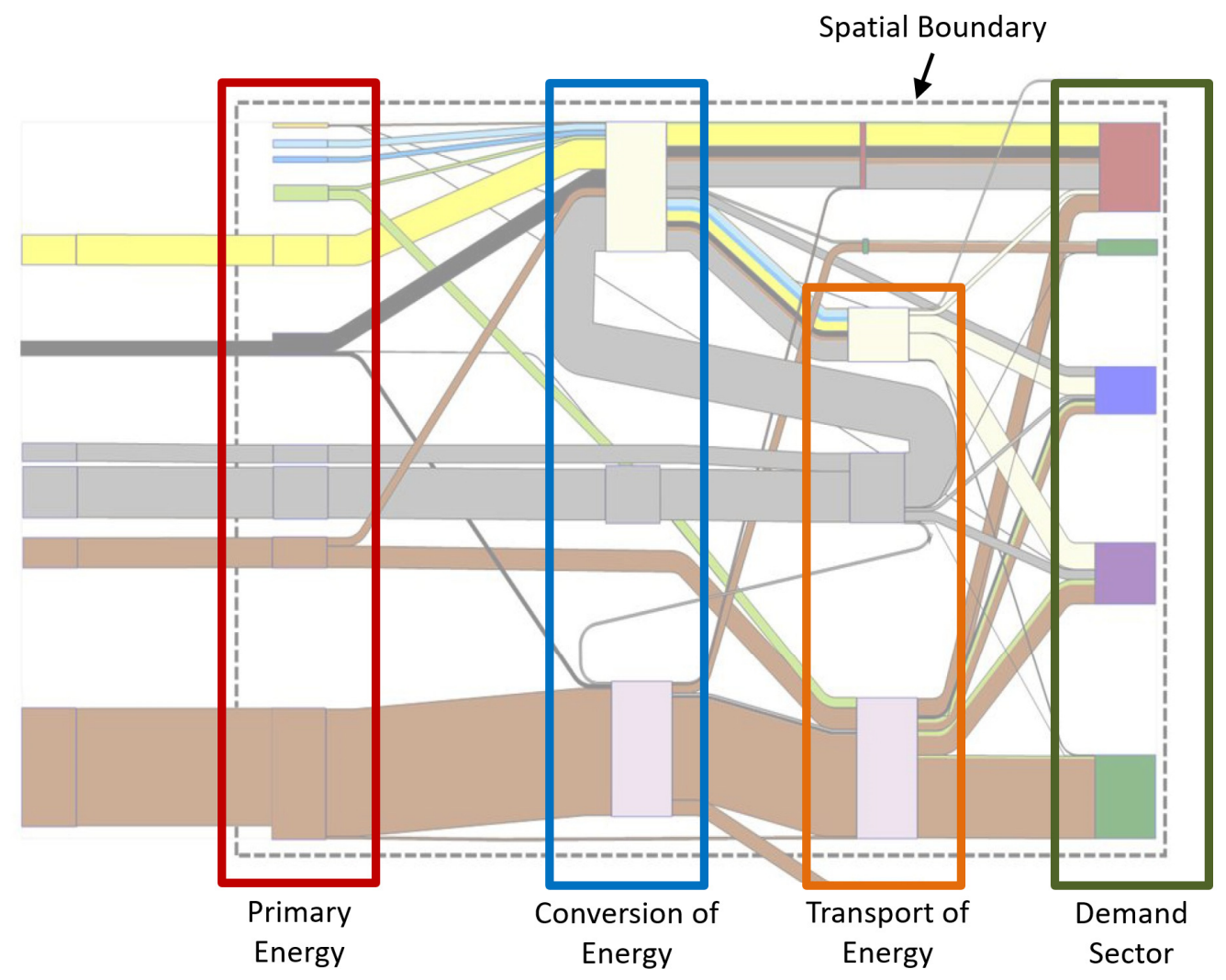

Figure 2: Energy sub-module conceptual framework (Adapted from López-Peña 2014 [66]). Sankey diagram multi-colored paths representing flows of different energy carriers (e.g. nuclear, oil, electricity etc.) passing through the smaller boxes representing different energy technologies (e.g. oil refineries, gas turbines, solar photovoltaics etc.). Larger boxes indicate different phases of the energy life-cycle (e.g. Primary energy, conversion of energy etc.). Dashed line represents the spatial boundary. 


\subsection{Water Model Framework}

The water sub-module can be conceptualized as presented in Figure 3 showing the flow of water through different processes. Each node (rectangle and oval) represents a mass-balance equation with the different colored lines representing parameters and variables. All flows into a node must equal all flows out of the node. Water can be of different qualities such as saline, potable, untreated, waste or recycled water.

This system is applied to each spatial sub-division over the chosen temporal sub-divisions. In Figure 3 the different boxes represent water entering or leaving the chosen spatial boundary. Yellow boxes represent exogenous parameters which define water entering the system and comprise of precipitation and ocean water. Green boxes represent water leaving the spatial boundary as runoff, environmental flows or waste water. Final demand consumption and non-served water are represented by the dashed-line box. At each node water can also leave the system either as evapotranspiration indicated by red lines or as leakages (green lines representing process leaks and pink lines representing distribution leaks). Certain nodes also have storage capabilities indicated by a blue line. Storage capabilities include snow and soil moisture at the "Precipitation Balance" node, ground water aquifer storage at the "Ground Water" node, reservoir storage at the "Reservoir" node and rainwater harvesting storage at the "Rainwater Harvesting" direct and central nodes. Each storage unit is constrained by maximum and minimum limits based on the existing and new installed capacity. Thus, for example, in each spatial sub-unit, water stored in reservoirs can never be greater than the capacity of reservoirs in the sub-unit. As seen in the figure a distinction is made between "Direct" users, who use water directly from the system and "Central" users, who are provided water by a central administration. Purification, waste water treatment and reclaimed water redistribution is included as a service provided by the central administration.

For each spatial and temporal unit the mass-balance is checked according to Equation 7 . Each spatial sub-unit is treated as a node and water flows within the sub-units are not considered. Changes in upstream runoff are reflected downstream within the same temporal sub-unit. Model outputs should thus be validated against known values for each choice of spatial and temporal unit size. Changes in storage for every temporal sub-unit occur as a result of the difference between water entering the system (from precipitation, desalination, inter-basin transfers and runoff from other regions) and water leaving the system (as evapotranspiration, inter-basin transfers and runoff leaving each region). Evapotranspiration is composed of interception evaporation, snow sublimation, plant transpiration, surface evaporation, soil evaporation and water consumed or evaporated as part of different conversion, distribution, treatment and end-use processes.

$\delta S(s, t) / \delta p=P(s, t)+D(s, t)+I_{\text {in }}(s, t)+Q_{\text {in }}(s, t)-V(s, t)-I_{\text {out }}(s, t)-Q_{\text {out }}(s, t)$

Where..

$s$ : Spatial sub-unit, $t:$ Temporal sub-unit, $S:$ Storage, $P$ : Precipitation

$D$ : Desalination, $I_{i n}:$ Inter-basin transfers in, $Q_{i n}:$ Runoff in

$V$ : Evapotranspiration, $I_{\text {out }}$ : Inter-basin transfers out, $Q_{\text {out }}:$ Runoff out 


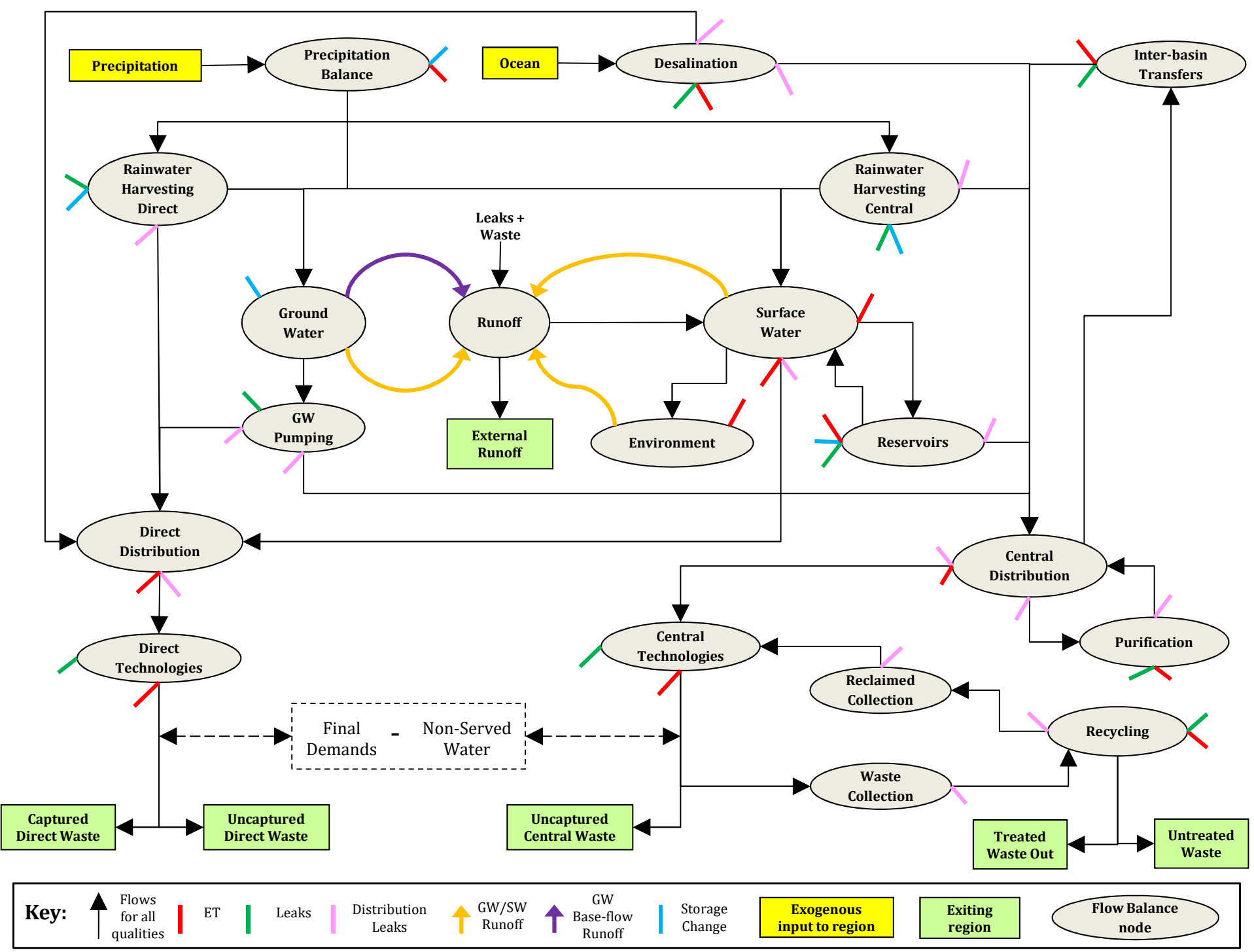

Figure 3: Water sub-module conceptual framework showing the flow of water volume tracked through different water processes. 
As an example, Figure 4 shows a close-up of the desalination node. The mass balance for this node is defined as shown in Equation 8a. Each of the lines in Figure 4 is represented by a term in Equation 8a. Comparing Figure 4 and Equation $8 \mathrm{a}$ it can be seen that $Q_{o 2 d}(s, d, q, t)$ represents the flow of water from the ocean to the desalination system. In all the equations $q$ represents the quality of water which can change after passing through a node. In this example water of "saline" quality is treated through desalination processes to produce water of "potable" quality. The mass balance is maintained for the total volume of water regardless of the quality. Several desalination processes can be defined and are contained in the set named $d$. Each $d$ process will have its own costs, losses, energy consumption and ability to process water to different qualities. Similarly the other flow lines from Figure 4 include water passing through desalination processes to central distribution captured by the variable $Q_{d 2 C}$ and to direct users in the variable $Q_{d 2 D}$. Leakages for each $d$ process are captured by the $Q_{d 2 L}$ term and leakages in the distribution systems by $Q_{C 2 L}$ and $Q_{D 2 L}$. Finally for each $d$ process some water will be consumed or evaporated and is captured by the $Q_{d 2 V}$ term.

Apart from the flow balance term, each process is also characterized by additional equations such as Equation $8 \mathrm{~b}$ and Equation $8 \mathrm{c}$ which define other constraints. Equation $8 \mathrm{~b}$ limits the flow of water through desalination processes to less than the sum of existing desalination processing capacity $P_{0}$ and newly invested capacity $P_{\text {Inv }}$. Equation 8c calculates the energy consumed by each desalination process based on the amount of water flowing to the distribution systems and the predefined energy parameters, $N(d)$.

Each node is defined by similar equations which maintain mass balance and also calculate energy, leaks, evapotranspiration and costs. Equations for each of the other nodes from Figure 3 are provided in the Supplementary Material.

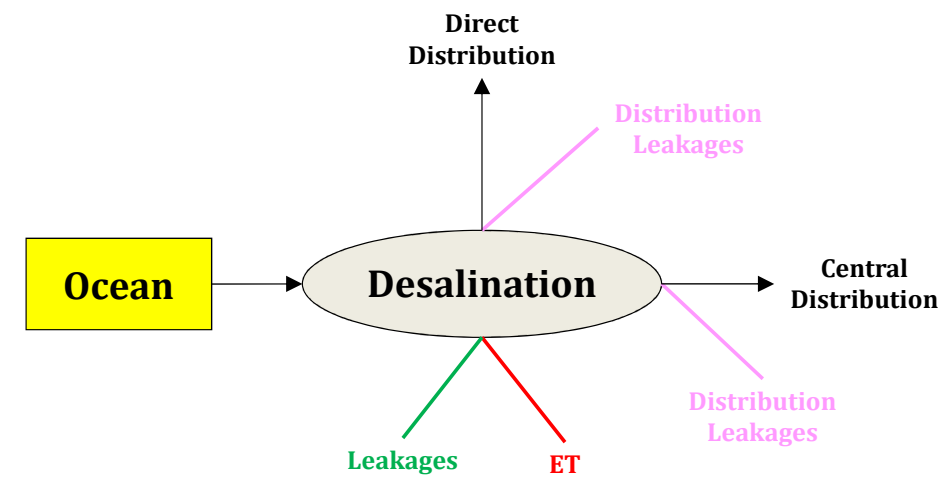

\begin{tabular}{|c|c|c|c|c|c|c|}
\hline Key: & $\begin{array}{l}\text { Flows for all } \\
\text { qualities }\end{array}$ & ET & Leaks & $\begin{array}{l}\text { Distribution } \\
\quad \text { leaks }\end{array}$ & $\begin{array}{l}\text { Exogenous } \\
\text { input to } \\
\text { region }\end{array}$ & $\begin{array}{c}\text { Flow } \\
\text { balance } \\
\text { node }\end{array}$ \\
\hline
\end{tabular}

Figure 4: Close-up of desalination flow balance node from Figure 3 


$$
\begin{aligned}
\sum_{q} Q_{o 2 d}(s, d, q, t) & =\sum_{q}\left(Q_{d 2 C}(s, d, q, t)+Q_{d 2 D}(s, d, q, t)+Q_{d 2 L}(s, d, q, t)\right. \\
& \left.+Q_{C 2 L}(s, d, q, t)+Q_{D 2 L}(s, d, q, t)+Q_{d 2 V}(s, d, q, t)\right) \\
\sum_{q} Q_{o 2 d}(s, d, q, t) & <P_{0}(d, s)+P_{I n v}(d, s) \\
E_{d s a l}(s, d, q, t) & =\left(Q_{d 2 C}(s, d, q, t)+Q_{d 2 D}(s, d, q, t)\right) \times N(d)
\end{aligned}
$$

Where..

$s$ : Spatial sub-unit, $d$ : Desalination type, $q$ : Water quality, $t:$ Temporal sub-unit

$Q_{o 2 d}$ : Water flow ocean to desalination, $Q_{d 2 C}$ : Water flow desalination to central distribution

$Q_{d 2 D}$ : Water flow desalination to direct distribution, $Q_{d 2 L}$ : Water flow desalination to Leakages

$Q_{C 2 L}$ : Water flow central distribution to Leakages, $Q_{D 2 L}$ : Water flow direct distribution to Leakages

$Q_{d 2 V}$ : Water flow desalination to evapotranspiration, $P_{0}$ : Initial desalination capacity

$P_{I n v}:$ New desalination capacity investments, $E_{d s a l}:$ Energy in desalination processes

$N$ : Energy consumed by desalination per unit volume of water processed

\section{Model Validation}

An example application of the model is developed for the case of mainland Spain. Spain is chosen as a case study because it has well managed river-basin authorities with detailed historical data for both energy and water. Furthermore, Spain is an interesting case for the water-energy nexus since it already suffers from regional water scarcity concentrated in the South-East which it can address with several different water technology options such as desalination, re-use or long distance transfers, each with different possible impacts on the energy sector [28, [70] [71. Spain also has access to a well balanced energy mix with renewable technologies, nuclear, traditional fossil fuels and bio-fuels, all possible candidates for further development, each with their own possible impacts on the water sector [72] 73] 34. Finally, Spain also has a well developed network of about 1200 dams offering storage capacity of about $55,000 \mathrm{hm}^{3}$ allowing for several opportunities for managing the water-energy nexus. The model can easily be applied to other countries or regions after replacing the relevant input parameters with those of the area of interest. Any changes in spatial and temporal scales should be evaluated carefully and take into consideration the actual time required for flow through spatial units versus the simplified nodal representation in the model. All new applications of the model should be revalidated by running the model for controlled scenarios with known results.

The model validation attempts to simulate the behavior of the water and energy systems in recent years. Estimates for the existing installed capacity and process parameters for the Spanish energy system are taken from López-Peña 2014 [66]. Estimates for the existing water system capacity are taken from various sources including the Spanish Ministry of the Environment (Ministerio de medio ambiente, Gobierno de España) 74 75], the Spanish National Commission of Energy (Comisi'on Nacional de Energía) [76, the Centre for Public Works Studies and Experimentation (Centro de Estudios y Experimentación de Obras Públicas (CEDEX)) 77, the Spanish National Transmission System Operator - Red Electrica (Red Eléctrica de España) [78] and the Spanish Ministry of Food and Agriculture (Ministerio de Agricultura, Alimentación y Medio Ambiente, Gobierno de España) [79. 
The common spatial sub-unit across the water and energy sectors is chosen as the river basin and the common temporal sub-unit is chosen as the month. Spain is divided into fifteen river basins as listed in Table 1 and shown in Figure 5. The key exogenous input parameters (Rainfall, energy demand and water demand) are based on average historical values. The historical mean precipitation from 1941 to 2010 from the Spanish Ministry of the Environment 80 is used. Energy demands in the model are specified by indicating the demand for energy services such as the number of passengers travelling a specific distance as discussed in Section 3.3 on the energy sub-module methodology. The demands for different energy services are adjusted so that the final energy to different sectors is similar to that of recent years. The exogenous water demands by sector are calibrated against the values provided in the online database of the Spanish Ministry of the Environment [81].

Table 1: River basins in Spain 74 75.

\begin{tabular}{l|c|c|c|c}
\hline Basin & Map Label & Area $\left.\mathbf{( k m}^{2}\right)$ & Coast $\mathbf{( k m )}$ & Rivers $(\mathbf{k m})$ \\
\hline Galicia Costa & GalCosta & 13,217 & 2,120 & 2,875 \\
Miño-Sil & MinoSil & 17,592 & 0 & 4,473 \\
Cantabrico Occidental & CantbrOc & 17,436 & 807 & 3,839 \\
Cantabrico Oriental & CantbrOr & 5,807 & 266 & 1,282 \\
Duero & Duero & 78,860 & 0 & 13,539 \\
Tajo & Tajo & 55,764 & 0 & 10,130 \\
Guadiana & Guadiana & 55,389 & 34 & 8,046 \\
Tinto,Odiel y Piedras & TintOdPdra & 4,751 & 214 & 871 \\
Guadalquivir & Guadalquivir & 57,228 & 73 & 9,701 \\
Guadalete y Barbate & GuadBarbte & 5,928 & 280 & 1,195 \\
Cuencas Mediterraneas Andaluza & CMedAndlz & 17,948 & 652 & 2,145 \\
Segura & Segura & 18,897 & 395 & 1,469 \\
Jucar & Jucar & 42,958 & 588 & 5,386 \\
Ebro & Ebro & 85,567 & 148 & 12,495 \\
Cuencas Interna de Cataluña & CICat & 16,494 & 795 & 2,786 \\
\hline
\end{tabular}

With the input parameters set, no additional infrastructure or capacity is allowed to be installed. The model is then run and key outputs are validated against historical values. The model optimizes the choices of energy and water technologies to meet the demands based on resource and capacity availability. Given the uncertainty, assumptions and level of aggregation across the sectors it is only attempted to roughly mimic historical values for the baseline case. In Figure 6 a the energy production from different sources is compared with historical values from 2000 to 2014 (US Energy Information Administration (EIA) [82] 82, British Petroleum (BP) chair on energy and sustainability in Spain [73]). The water model is checked by comparing the evapotranspiration generated per basin per month against historical values from 1941 to 2010 [75] as shown in Figure 6p. Evapotranspiration in the model is composed of precipitation evapotranspiration (which aggregates interception evaporation, snow sublimation and plant transpiration), surface water evaporation as well as water consumed or evaporated as part of different conversion, distribution, treatment and end-use processes.

One of the key advances made in this model is that of allowing simultaneous tracking of energy in the water system and water in the energy system. These nexus results are compared with the values published in the water-energy study on Spain by Hardy et al. 2012 83. It should be noted that the results from Hardy et al. 2012 [83] are not outputs of a model but based on an analysis of existing literature and the corresponding estimates of energy and water flows from the individual uncoupled systems.

Figure 6. shows the comparison between the model and the study for the water consumed by various energy processes. In addition to the differences in methodology, the two studies also use different resource consumption parameters based on different sources. For example, Hardy et al. 2012 [83 assume nuclear power to have a water consumption of $1,569 \mathrm{~m}^{3} / \mathrm{GWh}$ while in this study we consider nuclear power with 
once-through cooling technologies to have a water consumption of $1,558 \mathrm{~m}^{3} / \mathrm{GWh}$ and tower-cooled nuclear plants to have a consumption of $2,589 \mathrm{~m}^{3} / \mathrm{GWh}$. Water consumption parameters used in the model are based on an analysis of parameters from twenty different studies as presented in Khan et al. 2016 [69]. In this study, Spain was estimated to have a total nuclear capacity of approximately $7.3 \mathrm{GW}$ (4.1 GW tower-cooled and 3.2 GW with once-through cooling). The combination of the two types of plants results in a higher water consumption per $\mathrm{m}^{3}$ as compared to Hardy et al. 2012 83. In both models hydropower consumes about $20,000 \mathrm{~m}^{3}$ per GWh of energy output making it the largest energy consumer of water. However, the consumption of water by hydropower is based on the evaporation of water held in reservoirs and thus a higher hydropower production does not necessarily translate to more water consumption by hydropower.

Figure $6 \mathrm{~d}$ shows the comparison for energy consumed by different water processes. Energy consumption by the water sector in the model is about four times greater than that shown in Hardy et al. 2012 [83. The higher energy consumption in the model can be explained by the difference in the volume of water being processed considered in the two studies. Both studies assume about $34 \mathrm{~km}^{3}$ of water are delivered to final users. However, the major difference between the studies is that to deliver the $34 \mathrm{~km}^{3}$ of water to final users, Hardy et al. 2012883 estimate that $34 \mathrm{~km}^{3}$ of water is needed during extraction, $25.6 \mathrm{~km}^{3}$ during distribution and $2.8 \mathrm{~km}^{3}$ during waste management. Thus the total amount of water processed to deliver the final amount of $34 \mathrm{~km}^{3}$ is $63.4 \mathrm{~km}^{3}$. In our model in order to deliver the $34 \mathrm{~km}^{3}$, taking into consideration the losses and evaporation, considerably more water is needed to be processed before it is delivered. In the model $62 \mathrm{~km}^{3}$ of water is extracted during pumping groundwater, transferring surface water, desalination and rainwater harvesting of which a large percentage is lost due to leakages and evaporation consumption. The distribution network is estimated to have losses of $25 \%$ and the total water distributed is $67 \mathrm{~km}^{3}$. Finally $20.8 \mathrm{~km}^{3}$ of waste water is processed in the waste system which includes waste water treatment, recycled water treatment and distribution of waste and recycled water to users or back into the environment. In total the water processed in the model is $150 \mathrm{~km}^{3} /$ year as compared to $63.4 \mathrm{~km}^{3} /$ year in Hardy et al. 2012 [83] and this is the main reason for the considerably higher estimate of energy consumed by the water system in the model. 


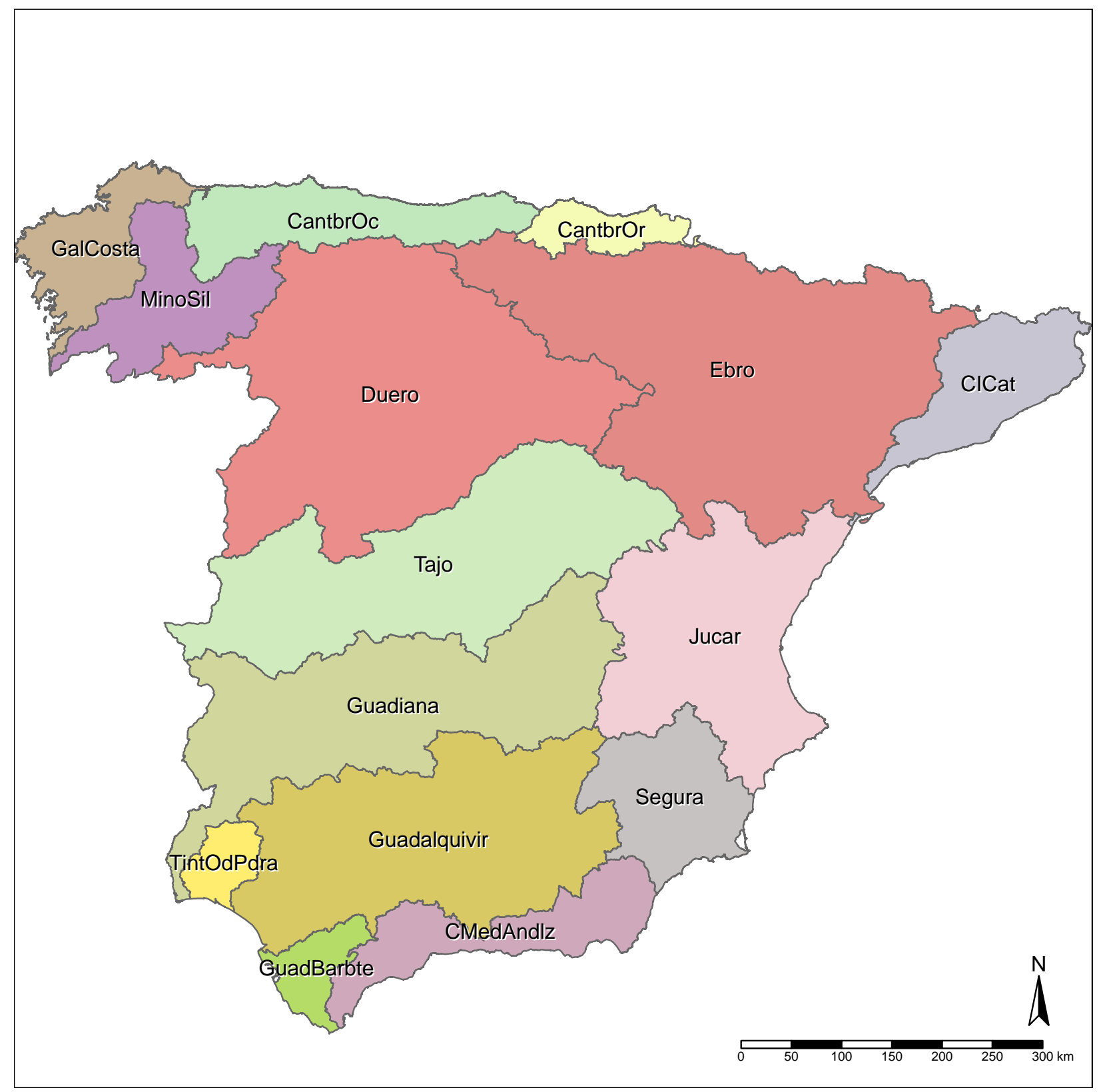

Figure 5: River basins in Spain. 
a) Final energy consumption

by energy source

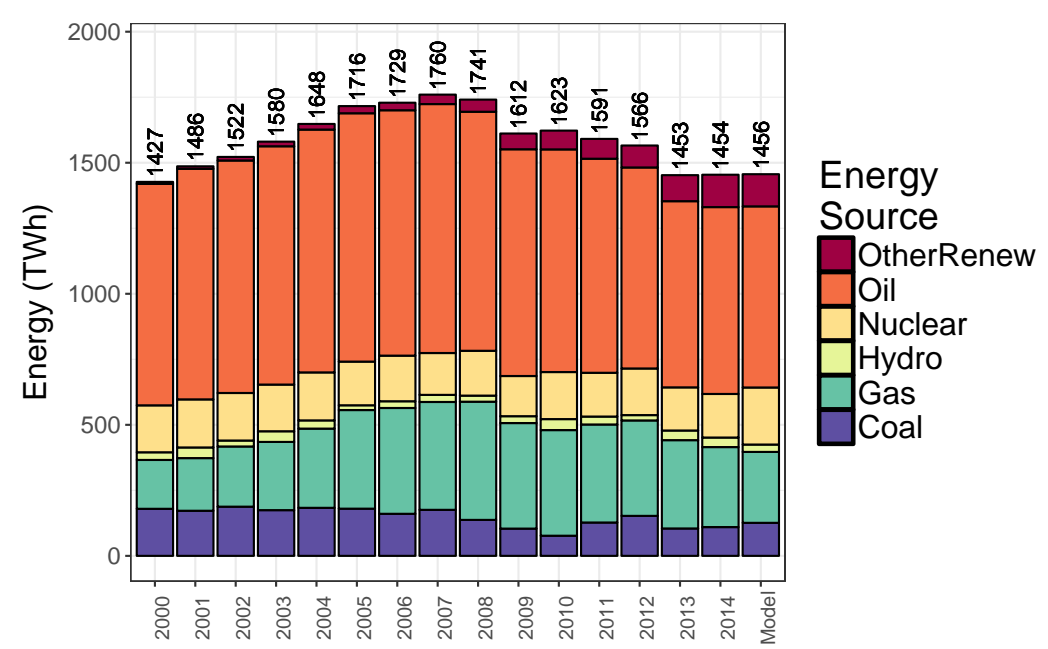

c) Water consumption by energy technology
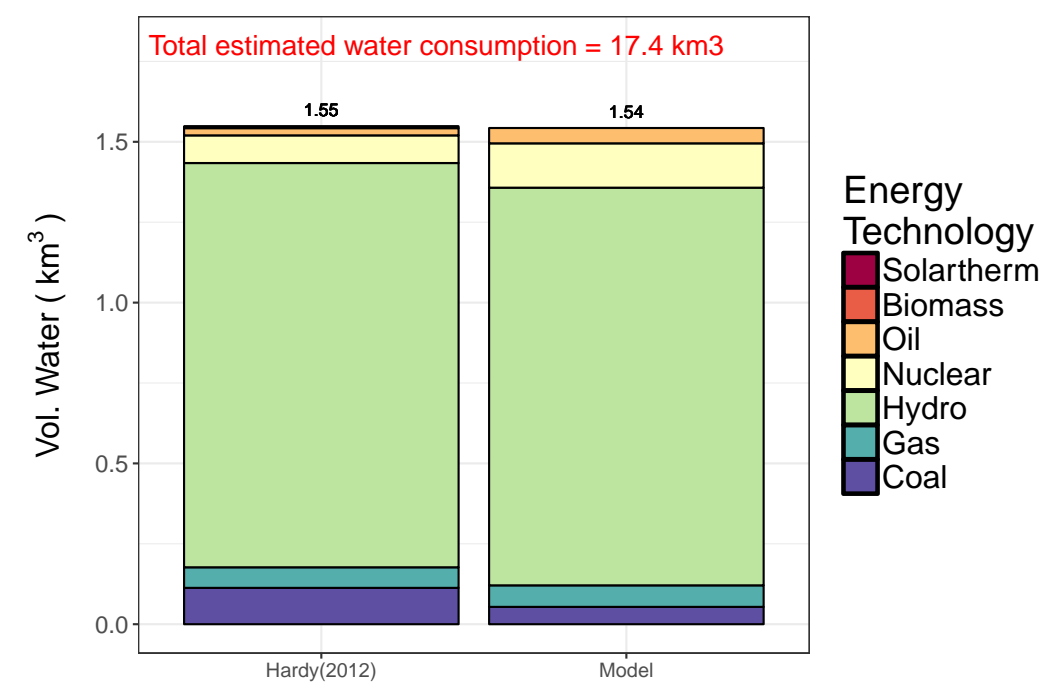

b) Monthly evapotranspiration (Red line: Model) (Boxplot: Average 1941-2010)

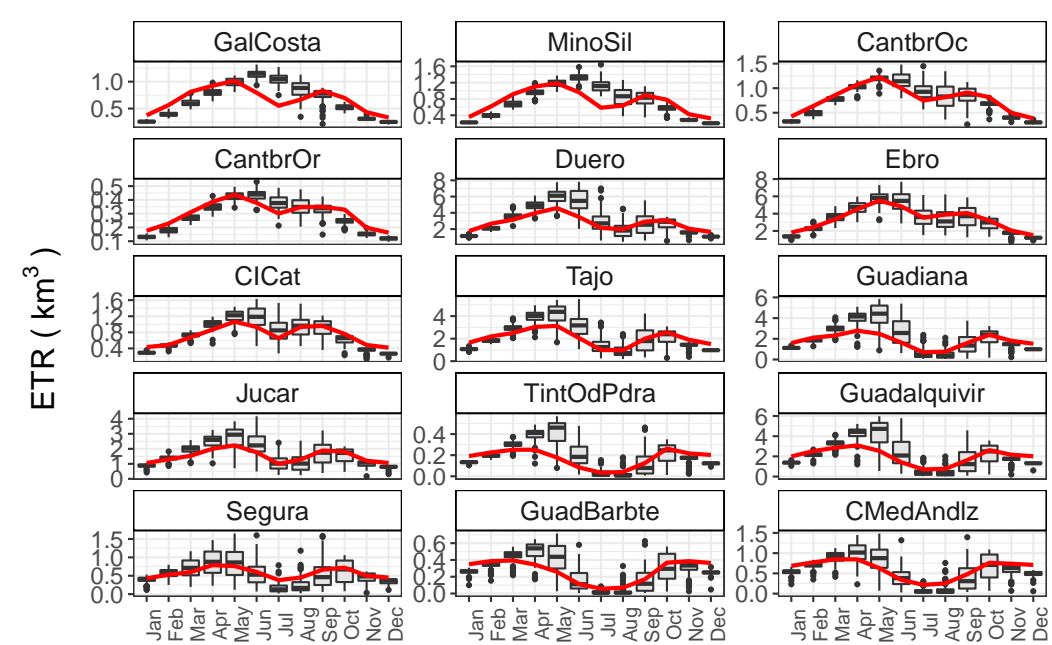

d) Energy consumption by water process

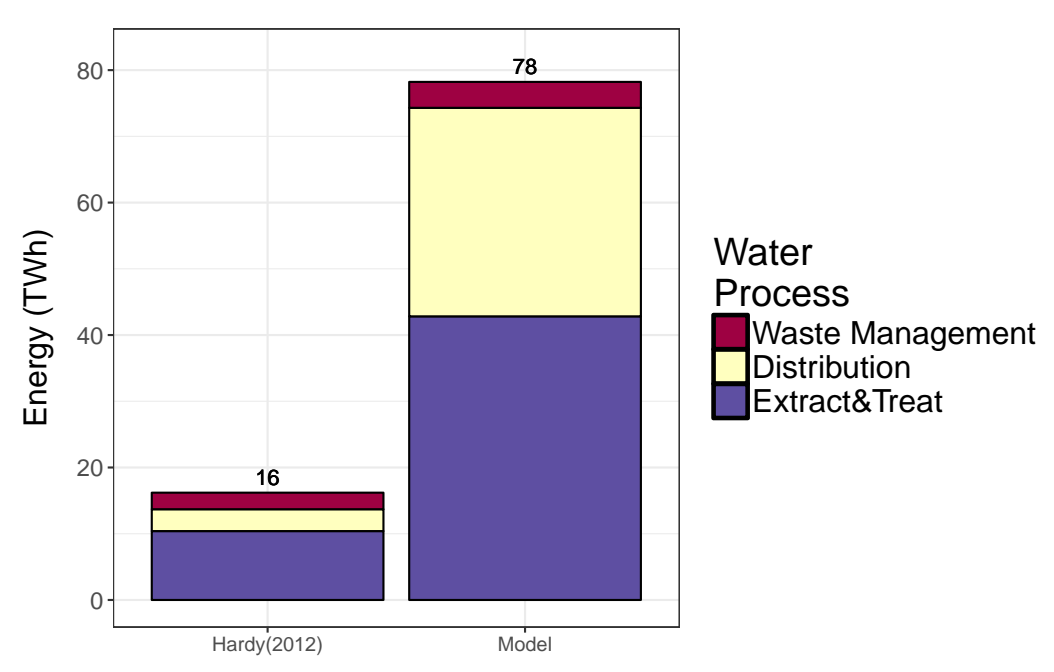

Figure 6: Model outputs compared with historical data. a) Final energy consumption compared with historical data 84] 73] 82]. b) Monthly evapotranspiration compared with historical data from the Spanish Ministry of Environment [75]. c) Water consumption by the energy system compared with data from Hardy et al. 2012 83]. Differences in values due to different water withdrawal and consumption parameters. d) Energy consumption in water processes compared with Hardy et al. 2012 [83]). Differences in values due to larger volume of water processed in model at earlier stages of water life-cycle to account for losses and evapotranspiration. 


\section{Future Scenario}

This section explores the advantages and opportunities of planning for future resource security using integrated modeling while at the same time demonstrating some of the capabilities and applications of the model.

Subsection 5.1 introduces the different model runs which will be used to demonstrate the differences between the integrated and non-integrated cases. Subsection 5.2 develops an example future scenario with increases in water demands, energy demands and temperatures as well as a decrease in precipitation. In Subsection 5.3 the benefits of an integrated model are explored by analyzing the differences between the plans and performance of the integrated and non-integrated approaches for the hypothetical scenario from Subsection 5.2. Starting out with the initial state of the validated model from Section 4 , both the integrated and non-integrated modes are used to make investment plans in the water and energy sectors for the new future scenario from Subsection 5.2. The non-integrated run does not consider water-energy inter-sector links during this planning phase. Next, with the planned capacity pre-installed for each case, the model is re-run without allowing any further investments and re-subjected to the future scenario. However, during the performance phase runs, the links between the water are energy sector are active for both the integrated and non-integrated runs. The consequences of ignoring the inter-linkages can thus be evaluated by comparing the results. In Subsection 5.4 the robustness of both the modes are investigated further in a sensitivity analysis by comparing the results of each mode for a wide range of variations in a number of uncertain variables.

\subsection{Model runs definition}

In order to analyze the impacts of ignoring water-energy nexus inter-links, several different runs of the model are planned as shown in Figure 7 The aim is to compare the capacity expansion plans of the model set to run in an integrated mode, in which the water-energy systems are interconnected, as shown on the right in Figure 7, with those of the model set to run in a non-integrated mode, as shown on the left. In the integrated mode the model calculates energy demands from the water sector and water demands from the energy sector endogenously and then optimizes technology investment and operation decisions (spatially and temporally) in both sectors accordingly. In this integrated mode the model also accounts for the impacts of water temperature changes on power plant cooling requirements. The non-integrated mode represents the traditional, isolated, individual sector-specific approaches to expansion planning, without considering any of the inter-sector links mentioned.

For each mode, the model is first used to calculate the corresponding optimal investment plan in the "Planning" phase runs as shown in the upper part of Figure 7. Next, the planned capacity is added to the original existing capacity and each of the plans is put to the test by running the model again for the same scenario as was planned for but this time without the option of new investments. This second phase is labeled the "Performance" phase and reflects the reality of a system in which the water and energy systems are interconnected.

\subsection{Scenario definition}

The model can be set up to compare different climate change and socio-economic scenarios. A scenario is defined using the input parameters shown in Table 2. As a simple example to demonstrate the outputs of the model, a hypothetical scenario is defined in which evapotranspiration potential is assumed to increase by $10 \%$, water temperature by $2.5^{\circ} \mathrm{C}$, while precipitation is assumed to decrease by $12 \%$. These values are roughly based on predictions made for Spain for the years 2041 to 2070 by the Centro de Estudios y Experimentación de Obras Públicas (CEDEX) [77] for various climate change scenarios. Energy demands were assumed to increase by $35 \%$ and water demands by $10 \%$. Given the wide range of possible socioeconomic and climate change scenarios, no attempt is made here to simulate a particular scenario or year and the values chosen are arbitrary from within the range of values studied. The sensitivity to changes in these uncertain parameters are explored later in Section 5.4. Even though in this example the changes are allocated uniformly across the spatial and temporal boundaries, much more refined scenarios capturing local and seasonal changes could be analyzed by employing different values across the spatial and temporal sub-units. 
NON-INTEGRATED
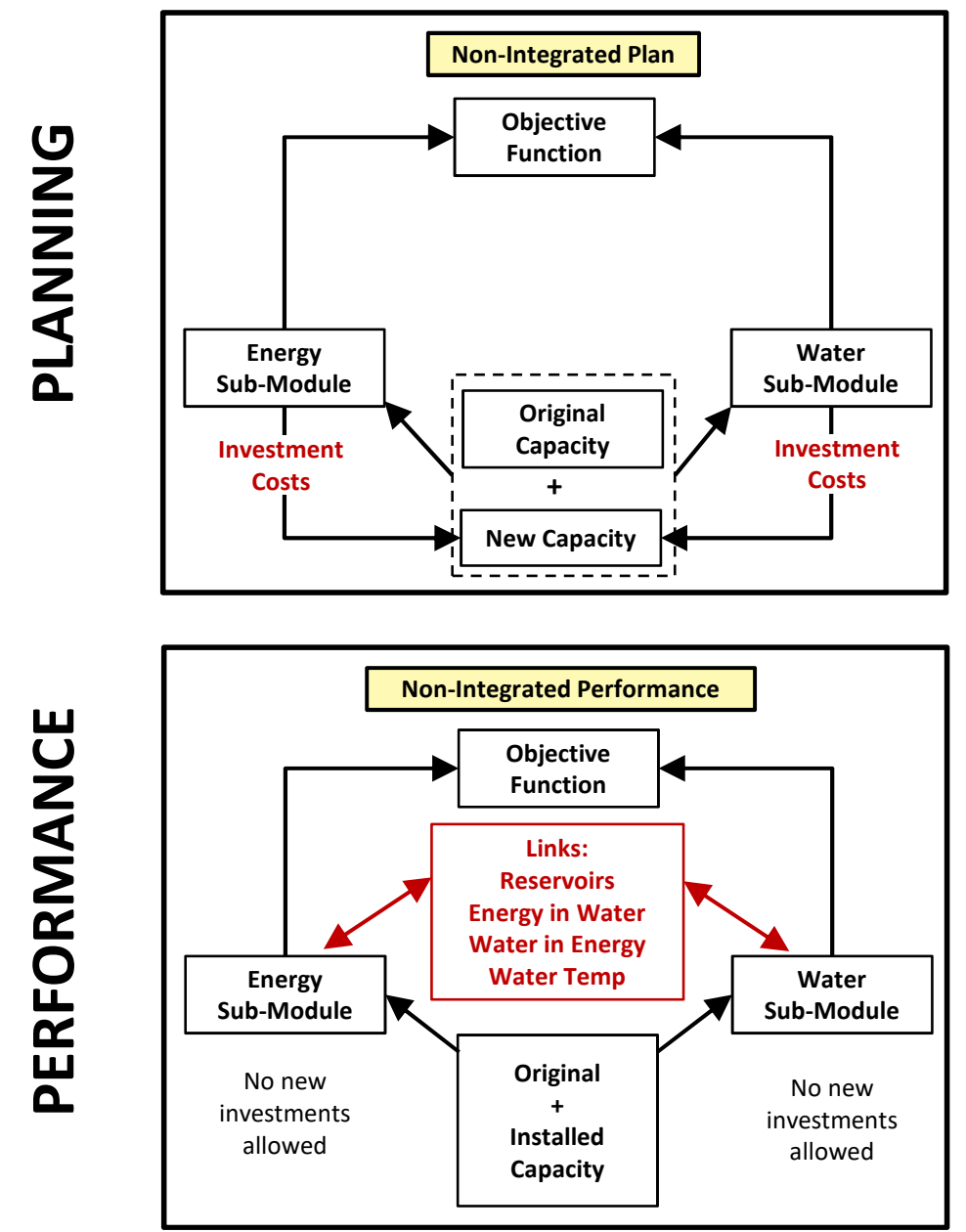

INTEGRATED
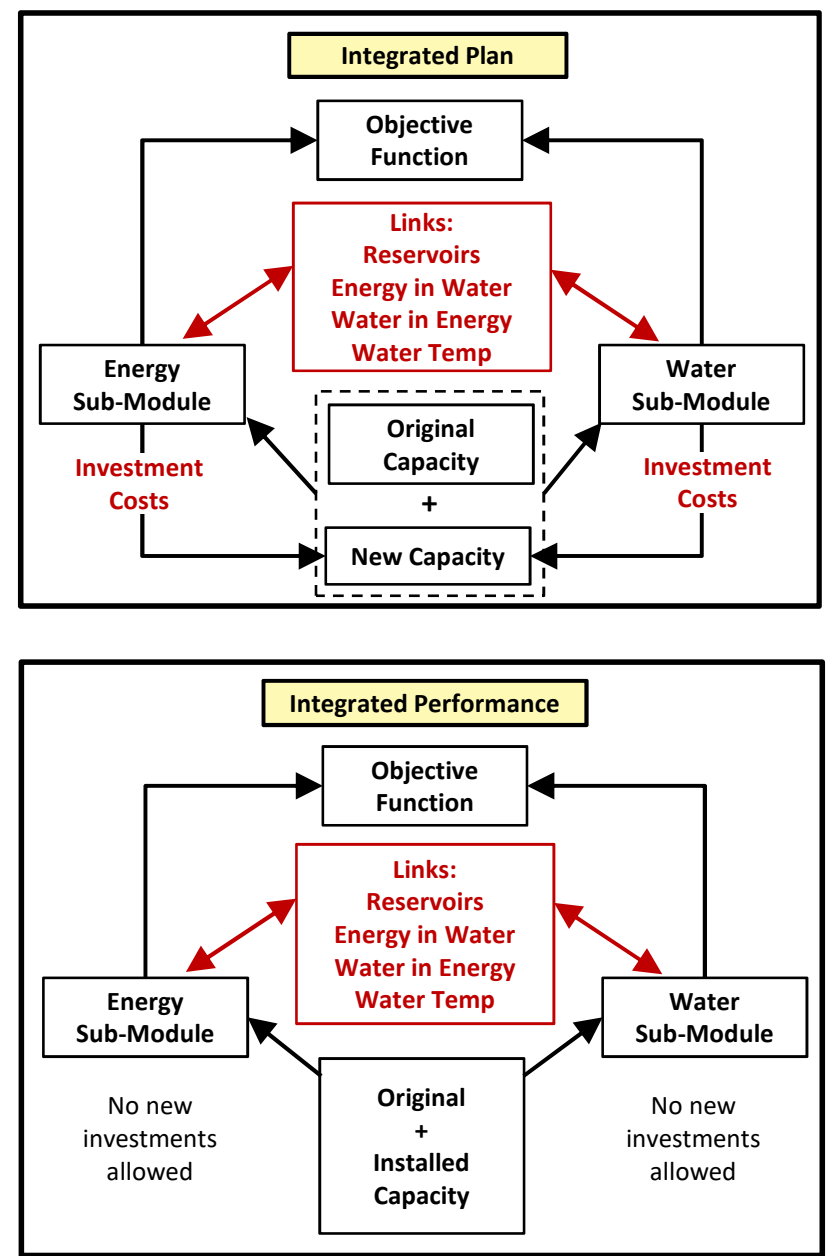

Figure 7: Model run definitions. Investments in new capacity is only allowed in the "Planning" runs. Planned investment capacity is then pre-installed in "Performance" runs. "Integrated" runs include the interlinks and feedback loops between the water and energy systems, while the "Non-integrated" does not. 
Table 2: Scenario definition (Changes from baseline).

\begin{tabular}{c|c}
\hline Parameter & Example Scenario \\
\hline Evapotranspiration Potential & $+10 \%$ \\
Temperature & $+2.5{ }^{\circ} \mathrm{C}$ \\
Energy Demands & $+35 \%$ \\
Water Demands & $+10 \%$ \\
Precipitation & $-12 \%$ \\
\hline
\end{tabular}

\subsection{Nexus Results}

Figure 8 gives a summary of the costs and investments made for each of the different model runs as shown in Figure 7. As seen in Figure 8 during the planning runs for the scenario described in Table 2, the "Integrated Plan" provides a plan which is about $0.6 \%$ (2.1 billion EUR) more expensive than that of the "Non-integrated Plan" run. This is because it considers the different water-energy interdependent constraints via the programmed links. The "Integrated" run, taking water constraints into consideration, invests in the more expensive and energy in-efficient but water-efficient dry cooling nuclear and gas cogeneration energy technologies as seen in Figure 8d. This choice of energy technologies allows the system more flexibility and thus ultimately lowers total costs during the performance runs in which the "Integrated Perf" run has total costs about 5\% less (19.1 billion EUR in this case study) than that of the "Non-integrated Perf" run. In Figure 8b, we note that during the performance phase the "Integrated" mode is able to serve the final energy using the planned investments, with imports and operation costs remaining similar to those as planned. However, for the "Non-Integrated" performance mode, the new capacity investment decisions prove insufficient after water-energy nexus interdependencies are included and additional costs are incurred in the form of increased imports and operation costs. In Figure 8b and c, "Installed Cap" costs in the performance runs refer to the planned investment costs and are not calculated during the performance runs but added on from the planning phase calculations. Figures 8 e shows that both modes invest in mainly desalination technologies with the non-integrated plan investing in more desalination to supply water for its planned investments in tower-cooled nuclear power plants.

Figure 9 shows the flows of energy and water through different processes to final demands for each run. As seen in Figure 9a, the "Non-integrated Plan" underestimates the total energy demands, because it does not account for the additional energy needs from the water system. This leads to a sub-optimal energy system plan in which, as seen in Figure $9 \mathrm{~b}$, during the performance phase, water constraints prevent the tower-cooled nuclear capacity in the "Non-integrated" run from operating and forcing the system to switch to the more abundant gas powered technology options. Similarly, in the water system in Figure 9 , the "Non-integrated Plan" underestimates the final water demands because it does not take into account the additional water consumed by the energy sector. As seen, in Figure 9d, this underestimation leads to changes in different water processes such as purification and recycling and higher overall water needs for the "Non-integrated Perf" run.

Figure 10 shows some key nexus results of process and temporal variations in the water consumed in energy processes and energy consumed in water processes. In Figure $10 \mathrm{a}$ and Figure $10 \mathrm{~b}$ we see how the "Non-integrated Plan" underestimates the energy needs of the water system and then during the performance phase it has a higher than expected consumption. This increase is a result of the additional water processing needs of the sub-optimal system. We see a similar result for the water consumed by the energy system in Figure 10. The "Non-Integrated" scenario performance run consumes more water as a result of the towercooled nuclear capacity in comparison to the dry air-cooled capacity available for the "Integrated" run. In all the runs water consumption by the energy sector is largely dependent on evaporation from hydro-electric reservoirs. Figure $10 \mathrm{~b}$ shows the temporal variations of the energy consumed by the water sector. The peak in summer months is due to the higher agricultural demands during those months. Figure 10 d shows the variation in total water consumed by the energy system throughout the year which also reflect changes in reservoir levels. 
Figure 11 shows the spatial distribution of the same nexus results. Figure 11 gives an idea of where the energy consumption in the water system is concentrated. The maximum energy consumption is concentrated in the Ebro and Tajo basins which have the largest demands for agricultural water and therefore the highest energy required to process this demand. Figure $11 \mathrm{~b}$, shows details on the spatial distribution of water demands from energy technologies. The highest energy is concentrated in the basin of Ebro for the "Nonintegrated" case. This occurs because the Ebro basin is where all the new tower-cooled nuclear capacity was installed and it is also the basin with the largest reservoir capacity, both of which are the largest consumers of water.

Figure 8 to Figure 11 showed some of the capabilities of the model to track water and energy resource flows throughout the life-cycle of the two systems and how these vary spatially and temporally. This degree of hard-linking between the two systems represented in equal detail, provides unique insights across both sectors, such as the ability to track impacts of exogenous changes on individual system processes in precise locations and time-periods. In addition, the model also tracks changes in water quality as it passes through each process, allowing for more accurate accounting of the energy needs for water treatment. Analyses like these can help policy makers to better understand the kinds of issues summarized in Section 2, such as increased water stress from expanding biofuel crop production or increases in energy demands from new water infrastructure projects. A similar comparison as done for the "Non-integrated" and "Integrated" cases can be set up for multiple policies or strategies. Regional impacts of inter-basin water transfers can be explored and compared to other local alternatives, such as increased water recycling and desalination. Similarly, impacts of changes in seasonal patterns and intensity of precipitation and temperature can be further explored for a variety of different scenarios. Section 5.4 expands further on how the model can be used to explore the robustness of strategies against variations in uncertain parameters.

\subsection{Sensitivity Analysis}

Given the large number of uncertain variables and assumptions in the model, a sensitivity matrix, shown in Figure 12, is created to evaluate the impacts of variability in several uncertain parameters on chosen output variables. All the charts in the matrix show the percentage difference between the outputs of the performance of the non-integrated plan vs the outputs of the performance of the integrated plan. The output variables measured are: total costs, energy system costs, water system costs, energy consumed by water and water consumed by energy. The horizontal dashed red line crossing the y axis at 0 represents no difference between the two plans. Values higher above the horizontal line represent an increasing difference between the non-integrated and integrated model outcomes. For example, in the upper left-most chart the highest point is at about $150 \%$ and means that the "Total Cost" for the non-integrated plan was $150 \%$ greater than the "Total Cost" of the integrated plan. Changes along the x-axis represent changes in the uncertain parameter being analyzed. So in the same upper left-most chart we see that the difference between the two plans increases as we move towards the right of the vertical dashed red line. The vertical red line represents the initial baseline value of the uncertain parameter. Moving towards the right of this line represents an increase in the parameter being analyzed while moving to the left indicates a decrease in the parameter.

Studying the different charts it is immediately clear that for all the output variables considered: total costs; energy system costs; water system costs; energy consumed by water and water consumed by energy; the non-integrated plan is more costly for almost all variations in the uncertain parameters except for "Water Demands". For "Water Demands" the integrated plan becomes more "expensive" than the non-integrated plan after an increase of $25 \%$. Going back to Table 2 from Section 5.2 we see that both plans were designed for a $10 \%$ increase in water demands. From Figure $8 \mathrm{~d}$ we see that the non-integrated plan ignored energyinefficiencies and invested in significantly greater amounts of desalination technologies to meet future water demands. Figure 9 shows that for the baseline case ( $0 \%$ on the x-axis), this choice of investment leads to increased energy consumption in the non-integrated performance and the feedback then leads to increased water consumption and higher total costs. The integrated plan remains more efficient for all the output variables up until an increase in water demands of $20 \%$ (Twice the planned increase of 10\%). For further increases, the installed capacity in the integrated plan proves to be insufficient while the non-integrated plan with additional desalination capacity is still able to meet demands. This leads to non-served water in the integrated plan which drives up water costs considerably. 
Another interesting observation is in the first column, where for increasing energy demands the difference between the total costs and energy costs continue to rise until about a $40 \%$ increase, after which the difference between the two models begins to diminish for the "water system costs", "water consumed by energy" and "energy consumed by water". This can be explained by the fact that with increasing energy demands both models face increasing non-served energy. The energy non-served is much higher in the non-integrated model causing the much high energy system costs. However, increasing non-served energy means the nonintegrated plan delivers less energy than the integrated plan and because of the feedback this means the difference between the two plans for the water processed, energy consumed in water and water consumed by energy also diminishes.

Overall Figure 12 shows that integrated planning, to assess the water and energy systems together, offers a much more robust strategy which maintains lower costs, lower water use and lower energy use relative to a non-integrated plan for a wide range of variations in the several uncertain parameters explored. 
a) Water and energy system total costs

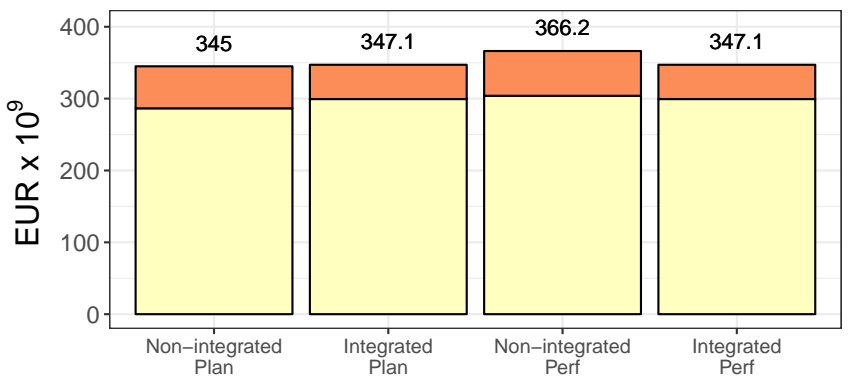

b) Energy system sub-costs

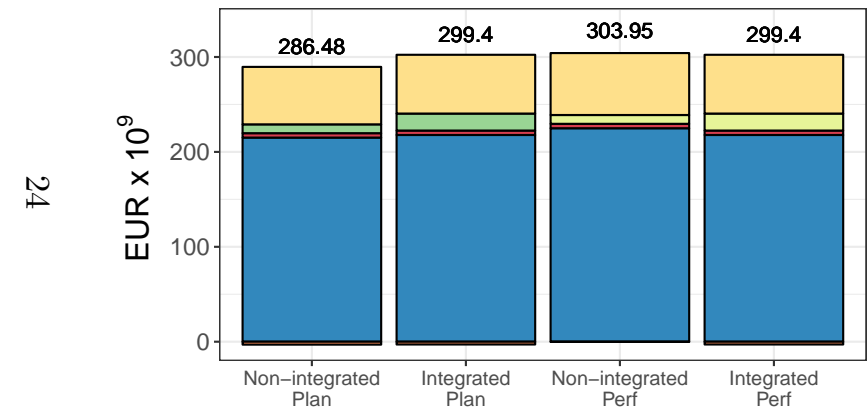

\section{Sub-cost $\square$ Imports Installed Cap Investments Emissions OnM \\ Export Rev.}

c) Water system sub-costs

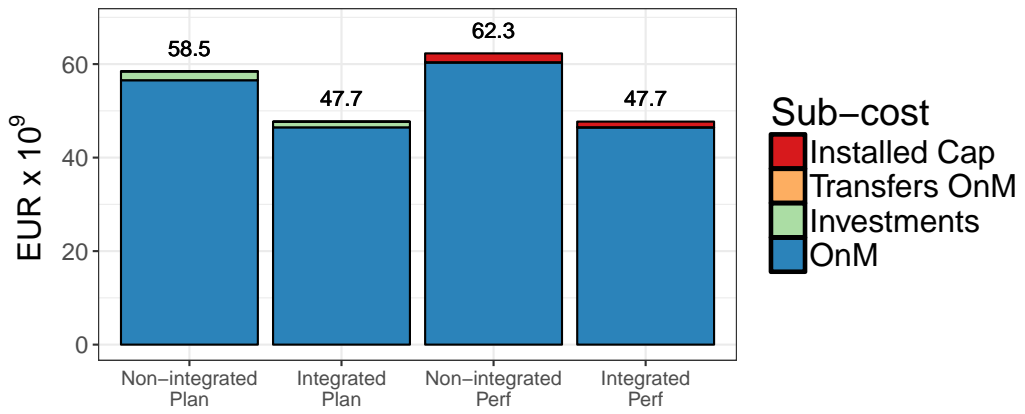

\section{d) New energy capacity investment plans}

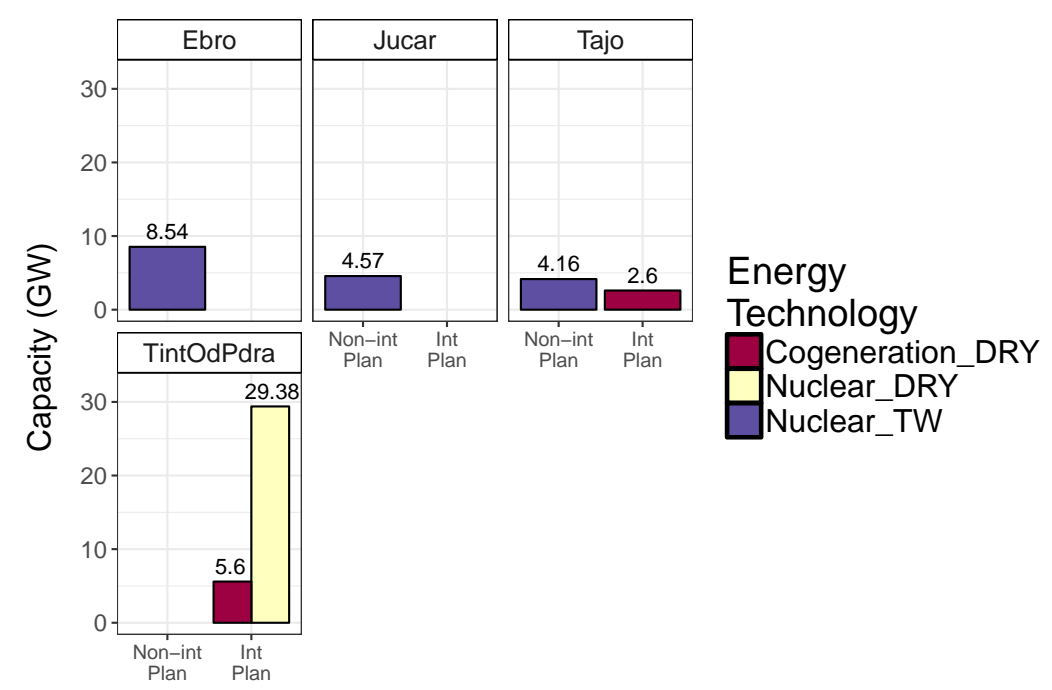

e) New water capacity investment plans

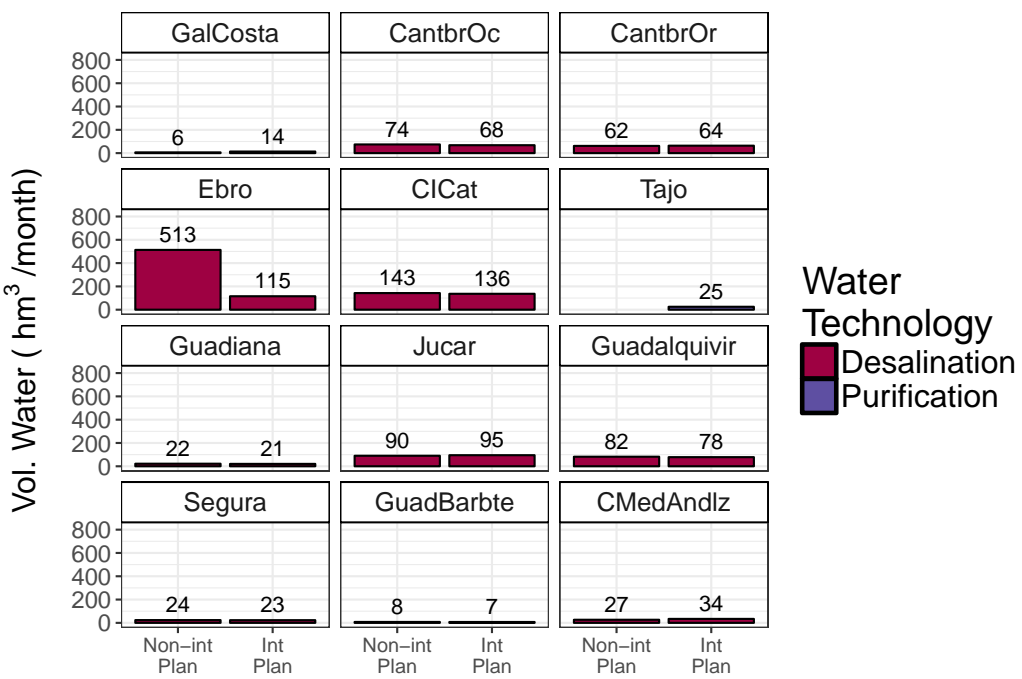

Figure 8: Costs and investments in the water and energy systems. a) Total combined costs for water and energy systems. b) Energy system sub-costs. c) Water system sub-costs. d) New energy capacity investments. Only technologies which were invested in are shown. The "Integrated" plan invests in more expensive but water-efficient dry air-cooled Nuclear technology. (Power plant cooling technologies: DRY - air cooled, TW - closed loop tower cooled, OT - once through cooled). e) New water capacity investments $\left(1000 \mathrm{hm}^{3}=1 \mathrm{~km}^{3}\right)$. 
a) Energy consumed by final sector

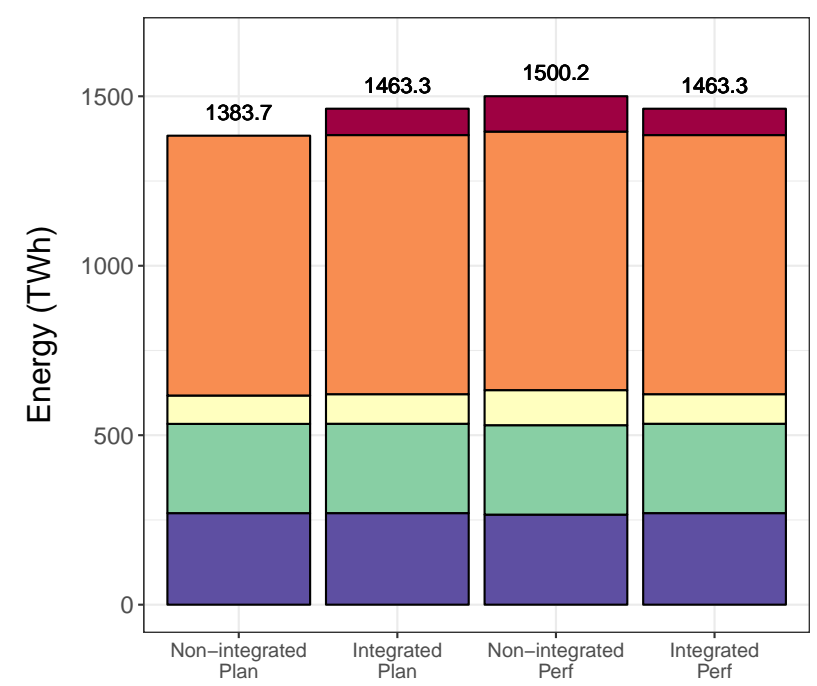

心

c) Water consumption by final sector

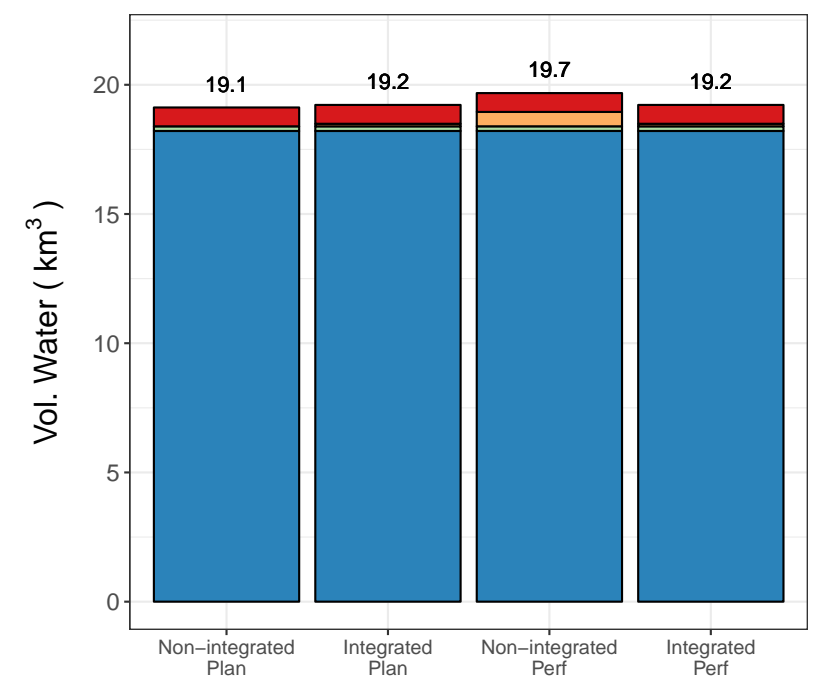

b) Local energy production

by energy source

Sector

Water

Services

Residential

Industry

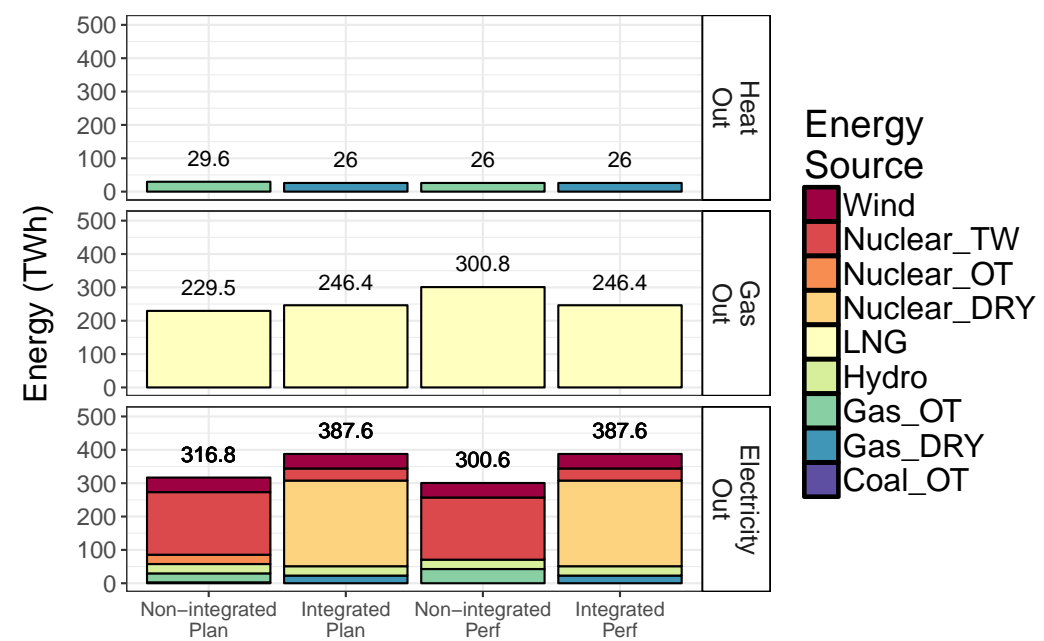

d) Water flows into

selected water processes

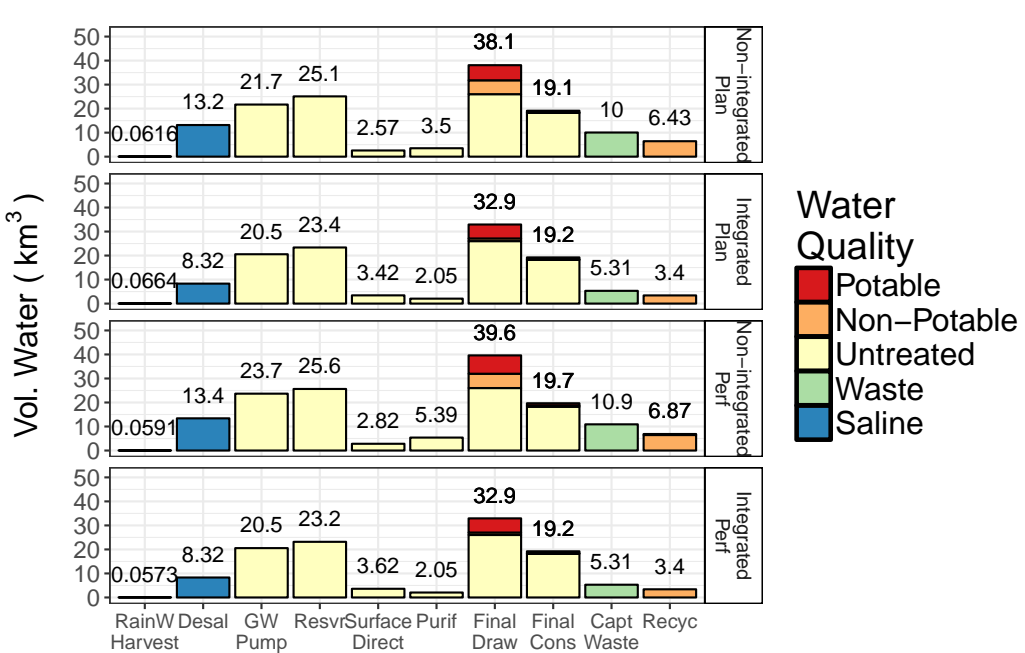

Figure 9: Water and energy production by source and final sectors. a) Energy consumed by final sector. b) Local energy production flows. In the "Non-integrated" performance, unplanned for electricity needs are met by additional gas plants (Power plant cooling technologies: DRY - air cooled, TW - closed loop tower cooled, OT - once through cooled). c) Water consumed by final sector. d) Water quality and quantity production flows into different processes. Does not show the losses and evapotranspiration in each process. 
a) Energy consumed in water processes

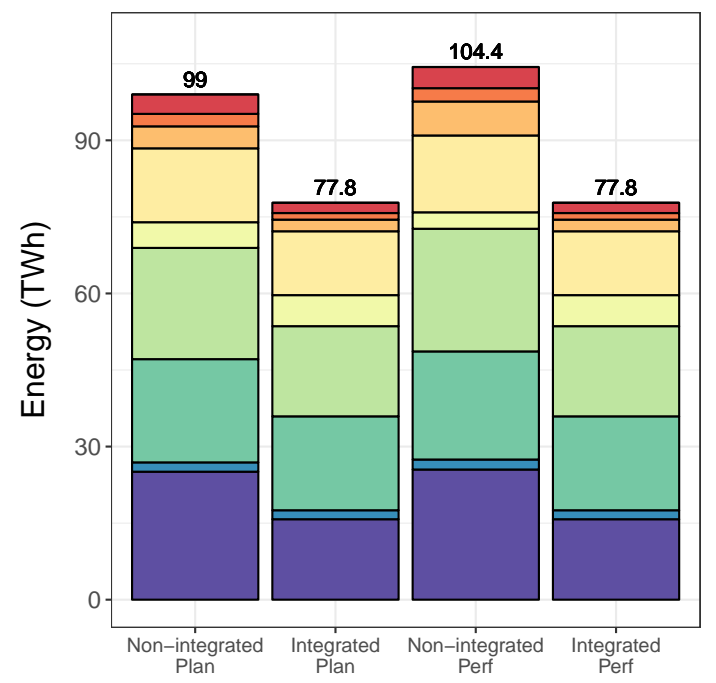

ธั

c) Water consumed in energy processes

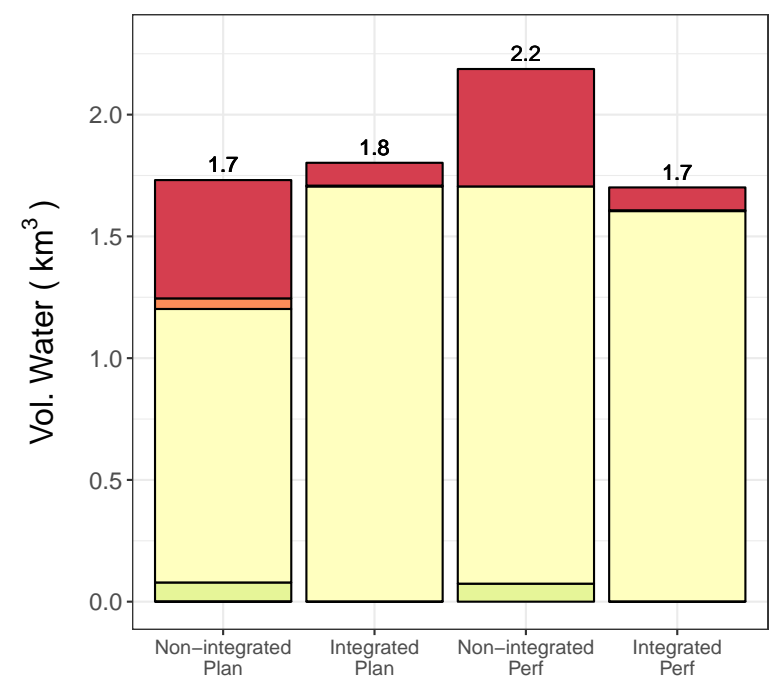

b) Energy consumed in water processes by month

Water

Processes

Waste Water Treat

Waste Dist

Reclaimed Dist

Recycling

Technologies

Purification

Distribution

Extraction to Dist

GW pumping

Desalination

Energy

Technology

Nuclear_TW

Nuclear_OT

Hydro Resv

Gas_OT

-Gas_DRY

Coal_OT

d) Water consumed in energy processes by month

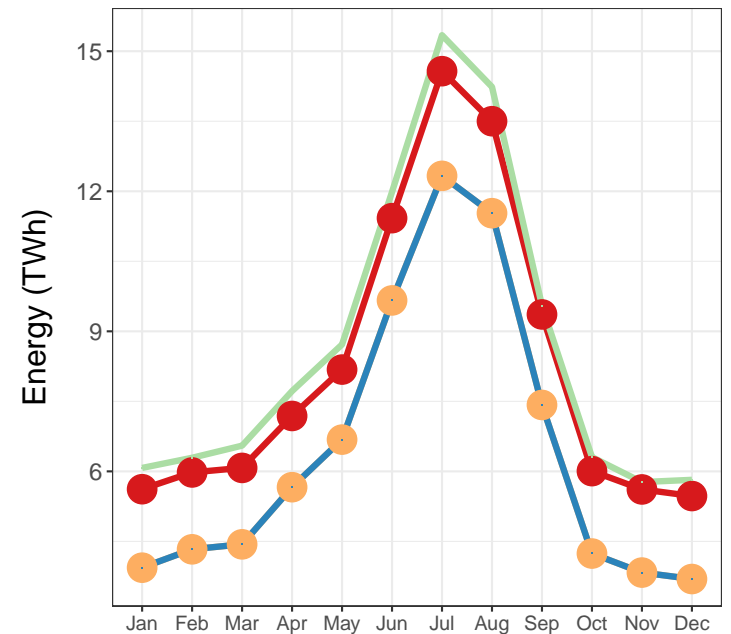

Policy

Non-integrated

Plan

Non-integrated

Perf

Pntegrated

Perf

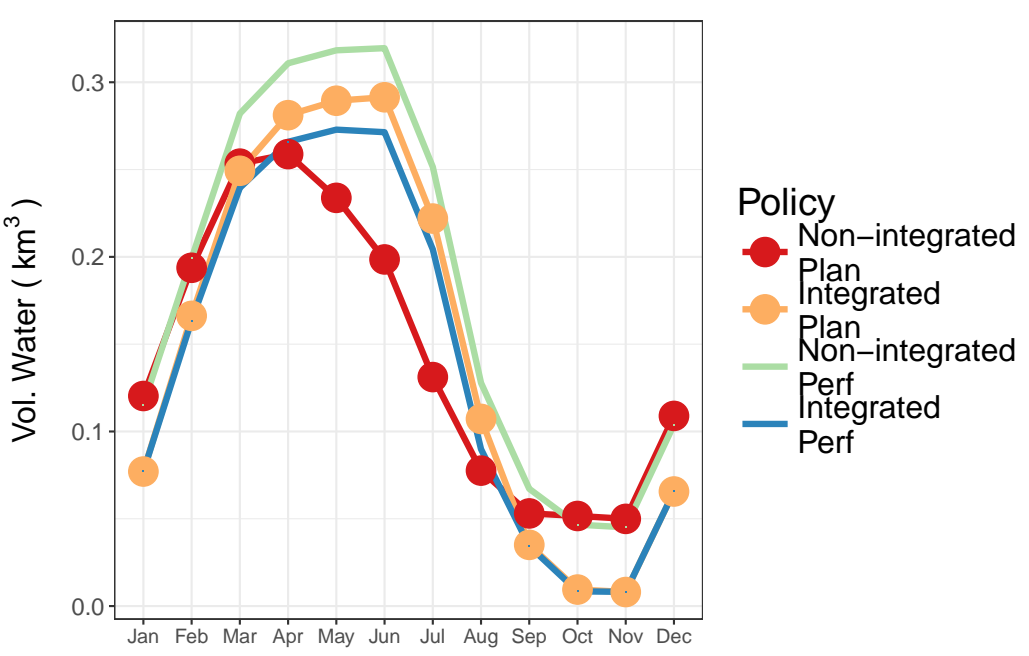

Figure 10: Water in energy and energy in water by process and temporal variations. a) Energy consumed by water processes. b) Monthly variations in energy consumption by water processes. c) Water consumed by energy processes (Power plant cooling technologies: DRY - air cooled, TW - closed loop tower cooled, OT - once through cooled). d) Monthly variations in water consumed by energy processes. Decline in water consumption primarily due to decreases in evaporation from reduced reservoir volumes. 


\section{a) Energy consumed in water processes by region}
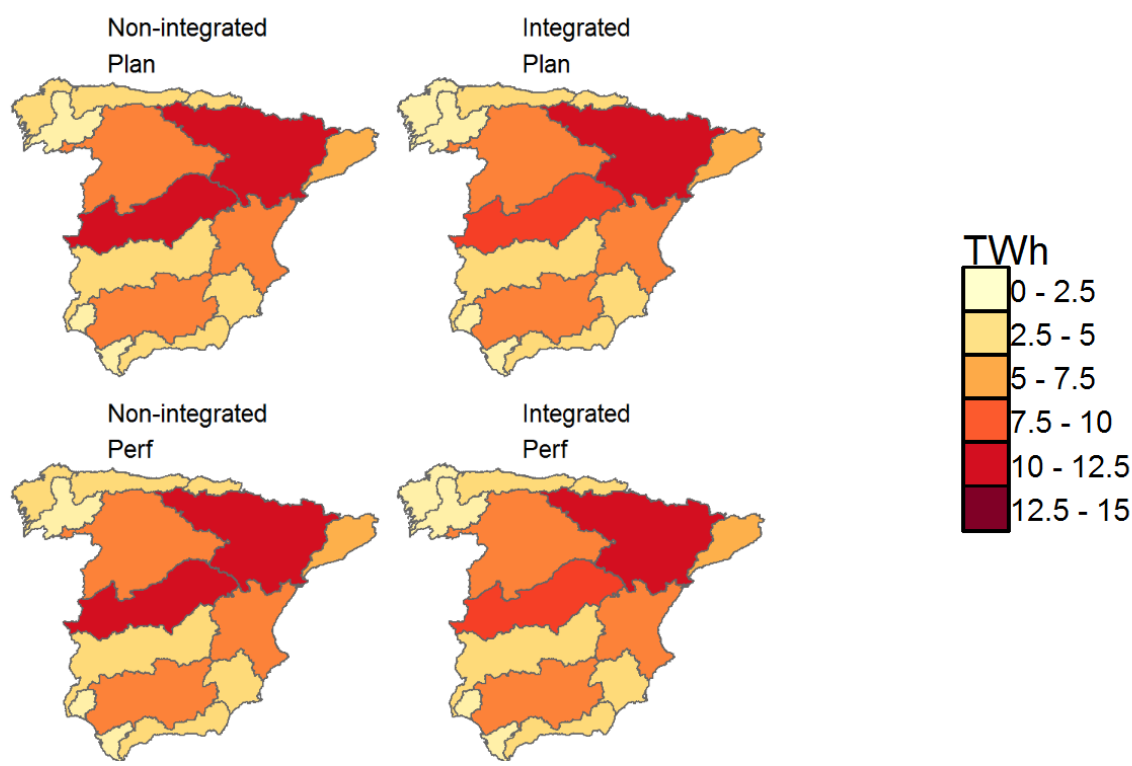

$0-12.5$

$12.5-15$

b) Water consumed in energy processes

by region

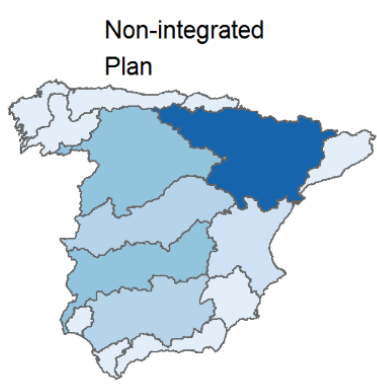

Non-integrated

Perf

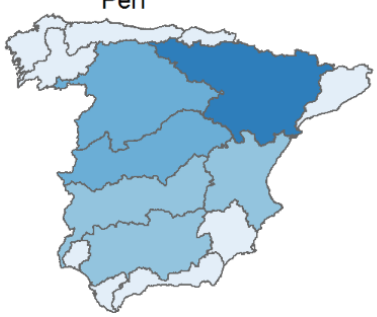

Integrated

Plan

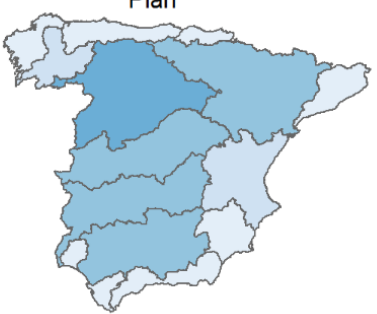

Integrated

Perf

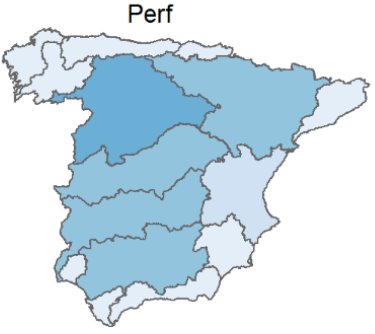

$\mathrm{km}^{3}$

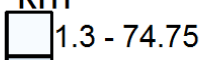

$74.75-148.2$

$148.2-221.65$

$221.65-295.1$

$295.1-368.55$

$368.55-442$

$442-515.45$

$515.45-588.9$

Figure 11: Spatial variation of water in energy and energy in water. a) Energy consumed in water processes by basin. Largest energy consumption in the Ebro river basin partially due to the higher agricultural demands. b) Water consumed in energy processes. Largest consumption in the Ebro river basin partially due to the larger reservoirs and tower-cooled nuclear capacity. 
Energy

Demands
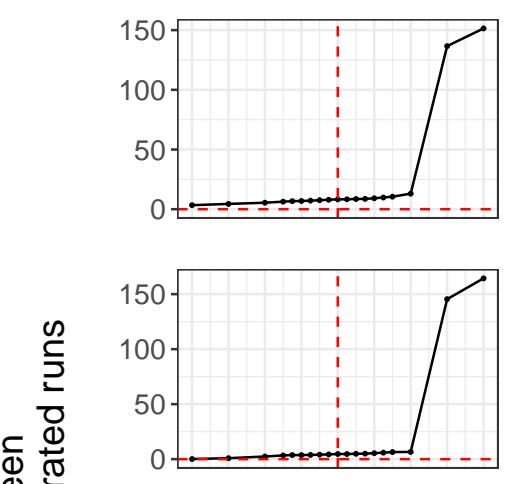

(ำ

这

음
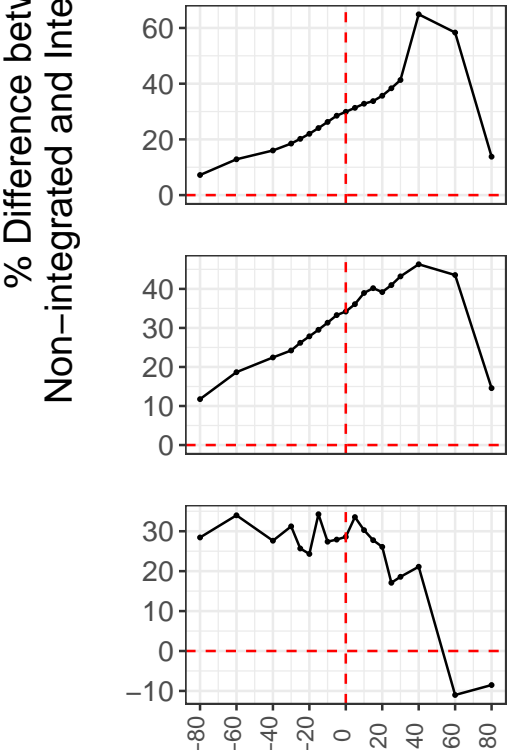

Emissions

Limits
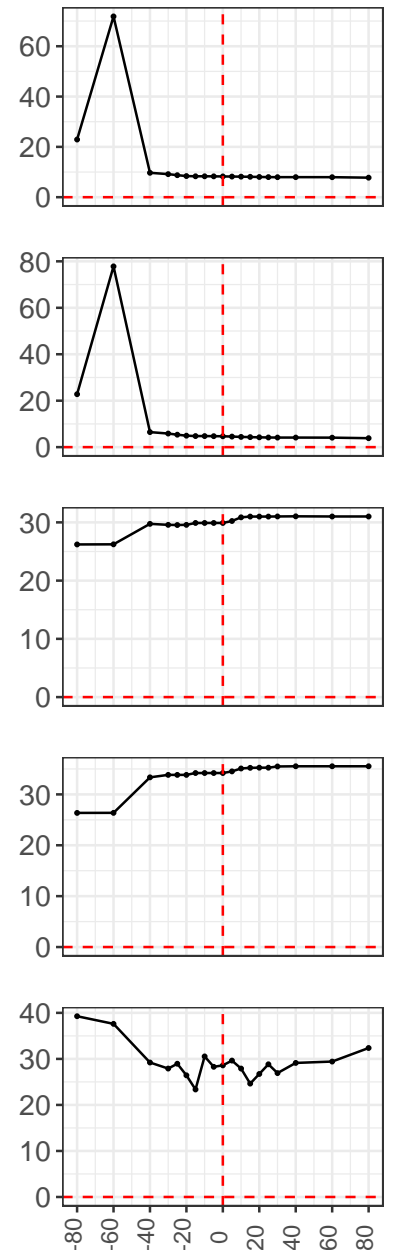

Water

Demands
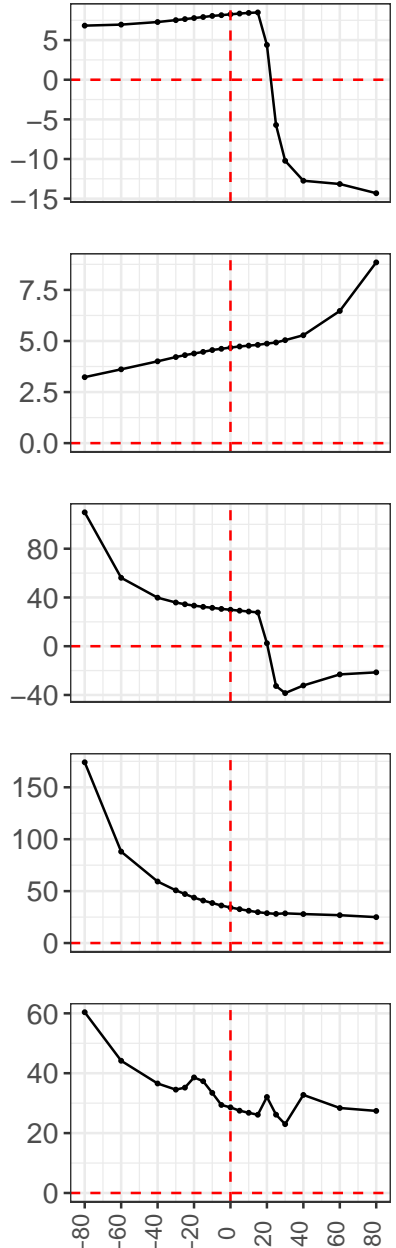

Precipitation

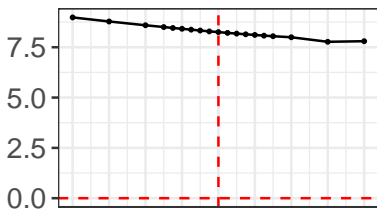

Total

Cost

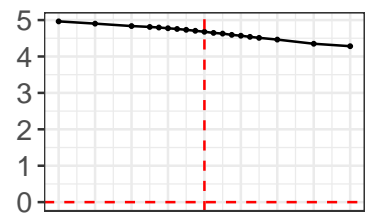

Energy

Cost

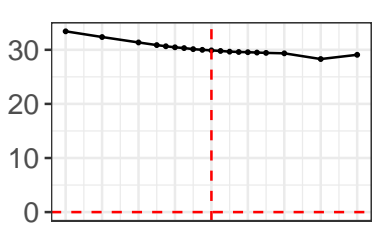

Water

Cost

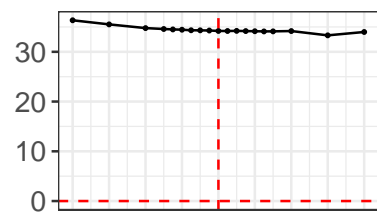

Energy

in Water

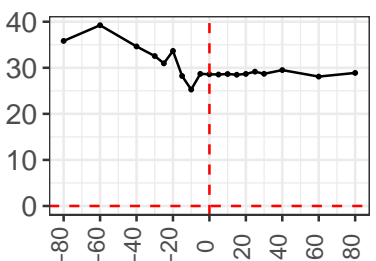

Water

in Energy

\section{Change in \%}

Figure 12: Sensitivity analysis matrix. Horizontal axis showing \% changes in four uncertain parameters: Energy demands, emission limits, water demands and precipitation. Each column of charts in the matrix represents each of the uncertain parameters respectively. Vertical axis showing the \% difference between the "Nonintegrated" and "Integrated" modes for the value of one of four output variables: Total cost, energy cost, water cost, energy consumed in water and water consumed in energy. Each row of the matrix represents one of these output variables. Values above the horizontal red line indicate the \% by which the non-integrated model results are greater than those of the integrated model. Left of the vertical red line $(0 \%)$ indicate decreasing variable values while right of the line indicate increasing variable values. 


\section{Limitations}

As discussed before, the model is a linear optimization program which automatically leads to several limitations as a result of simplifying reality into linear equations conforming to the optimization algorithm. Several non-linear relationships such as reservoir hydro-energy potential or changes in groundwater heads are linearized. The impacts of these assumptions vary depending on the particular system being evaluated. For example, a constant head is assumed for reservoir hydro-energy output calculations and the resulting energy outputs, calculated from the linear correlation assumed, show increasing deviations from historical records as the amount of outflow increases. The deviations become significant only for outflows which are greater than one standard deviation from the historical mean from 1980 to 2012 . The consequences of such assumptions are further intensified by the degree of aggregation of different processes over spatial and temporal sub-units.

Another limitation is that the partial equilibrium model in this paper focuses on the water and energy sub-sectors with other socio-economic parameters taken as fixed exogenous inputs. Future developments of the model can expand the model to include endogenous variable demands from other sectors such as the agricultural and food sector. It should be noted that any limitations apply to all the runs uniformly and given that the main purpose of the study was to evaluate the differences between the integrated and non-integrated runs these limitations play a smaller role in the final conclusions.

\section{Conclusions}

A review of past water-energy nexus studies showed that a more holistic approach, addressing both the energy and water systems uniformly across their complete life-cycles was needed to tackle the increasing interdependent constraints across both sectors. In the past, creating such a model has been a challenge particularly because of the differences in the physical, spatial and temporal characteristics of the water and energy systems and their corresponding parameters.

This paper overcomes some of these issues by identifying key water-energy nexus links and then incorporating these into a single hard-linked linear programming model. The model tracks the flows of both water and energy systems throughout their entire life-cycles. The model outputs also capture the spatial and temporal variations in these life-cycle flows across different scenarios and model settings. Specific "nexus" outputs track use of water in energy processes and energy in water processes. Keeping in mind the needs of different stakeholders, the model is made flexible allowing users to modify spatial and temporal boundaries as well as to refine key process definitions and adjust the weighted multi-objective function as needed.

The model is applied to an example case study in mainland Spain, for a specific future scenario (changes in Evapotranspiration by $+10 \%$, temperature by $+2.5{ }^{\circ} \mathrm{C}$, energy demands by $+35 \%$, water demands by $+10 \%$ and precipitation by $-12 \%$ ). Planning for the additional constraints as a result of taking water-energy links into consideration in the "Integrated" run, requires an additional $0.6 \%$ of the total water-energy system costs of the "Non-Integrated" run. However, when tested in the performance phase the "Integrated" plans prove to be more efficient from both an economic and resource perspective. For the current case study, final costs are 5.2\% (19.1 billion EUR) cheaper, final energy consumption 2.5\% (36.9 TWh) less, final water consumption $2.5 \%\left(0.5 \mathrm{~km}^{3}\right)$ less, energy consumption by the water sector $25.5 \%(26.6 \mathrm{TWh})$ less and water consumption by the energy sector $22.7 \%\left(0.5 \mathrm{~km}^{3}\right)$ less for the "Integrated" mode versus the "Non-Integrated" mode. In an integrated mode the model considers possible water constraints and invests in water efficient dry-cooling technologies. The reduced water demands results in less processing of water and thus less energy. The model also allows for easy evaluation of spatial and temporal variations in the energy-water demands, production and cross sector interdependencies.

With increasing populations, urbanization, non-renewable resource use and pollution in several regions of the world, water and energy resources are under increasing stress. Energy policies to limit emissions can be met with many alternatives, several of which, such as concentrated solar power, biofuels or nuclear power can have important impacts on water demands. Decreasing localized freshwater resources lead planners to search for water supply security alternatives such as desalination, inter-basin water transfers, increased treatment and water re-use. The long-term energy implications of these proposals need to be considered 
when examining their feasibility. In some situations, decoupling energy dependency and water, such as in the case of solar-powered groundwater pumping can lead to over-use of non-renewable resources leading to decreased water quality and increased aquifer vulnerability. This paper presents a new methodology which allows planners and policy makers to explore all these issues in detail, pinpointing critical individual processes in both the water and energy systems as well as where and when the impacts become most important. Each detail can be further analyzed for changes in socio-economic and climatic pathways. The benefits of integrated analysis become even more important when considering uncertainty. A sensitivity matrix is used to show that an integrated plan is more robust for a large range of uncertainty in several parameters, such as demand patterns, policy constraints and resource availability.

In conclusion, this paper shows that integrated planning tools can play a critical role in enhancing the understanding of the impacts of water and energy policies across both sectors and lead to improved resource security, increased resource use efficiency as well as lower total system costs.

\section{Acknowledgements}

The study was funded by the Education, Audiovisual and Culture Executive Agency (EACEA) of the European Commission as part of the Erasmus Mundus Joint Doctorate in Sustainable Energy Technologies and Strategies (SETS). The authors would also like to acknowledge the support of the Fundación Canal, Spain as well as the support provided by the International Institute for Applied Systems Analysis (IIASA) during the Young Scientist Summer Program (YSSP).

\section{References}

[1] D. J. Rodriguez, A. Delgado, P. DeLaquil, A. Sohns, Thirsty energy, Tech. rep. (2013). URL http://www . dun-eumena.com/reagri/upload/files/789230WPOBox377361B00PUBLIC0.pdf

[2] United Nations World Water Assessment Programme (WWAP), United Nations World Water Development Report 2014: Water and Energy United Nations Educational, Scientific and Cultural Organization (UNESCO), 2014. URL http://unesdoc.unesco.org/images/0022/002257/225741e.pdf

[3] Thinking about water differently: Managing the water-food-energy nexus Asian Development Bank (ADB), 2013. URL http://adb.org/sites/default/files/pub/2013/thinking-about-water-differently.pdf

[4] US Department of Energy (USDOE), The waterenergy nexus: challenges and opportunities USDOE, 2014. URL http://energy.gov/sites/prod/files/2014/07/f17/Water $\% 20$ Energy $\% 20$ Nexus $\% 20$ Full $\% 20$ Report $\% 20$ July $\% 202014$. $\mathrm{pdf}$

[5] World Business Council for Sustainable Development (WBCSD), Water, food and energy nexus challenges World Business Council for Sustainable Development (WBCSD) (2014). URL http://www.gwp.org/Global/ToolBox/References/Water, $\% 20$ Food $\% 20$ and $\% 20$ Energy $\% 20 \mathrm{Nexus} \% 20 \mathrm{Challenges} \%$ 20(WBCSD , \%202014).pdf

[6] World Resources Institute (WRI), Water-energy nexus. Business risks and rewards WRI (2016). URL https://www.ge.com/sites/default/files/Water-Energy_Nexus_Business_Risks_and_Rewards.pdf

[7] International Renewable Energy Agency (IRENA), Renewable energy in the water, energy and food nexus IRENA (2015). URL http://www.irena.org/documentdownloads/publications/irena_water_energy_food_nexus_2015.pdf

[8] World Economic Forum (WEF) Water Initiative and others, Water security: the water-food-energy-climate nexus, Island Press, 2011.

[9] A. S. Stillwell, C. W. King, M. E. Webber, Desalination and long-haul water transfer as a water supply for dallas, texas: A case study of the energy-water nexus in texas, Texas Water Journal 1 (1) (2010) 33-41.

[10] A. Dubreuil, E. Assoumou, S. Bouckaert, S. Selosse, N. Mal, et al., Water modeling in an energy optimization frameworkthe water-scarce middle east context, Applied Energy 101 (2013) 268-279.

[11] M. T. van Vliet, J. R. Yearsley, F. Ludwig, S. Vögele, D. P. Lettenmaier, P. Kabat, Vulnerability of us and european electricity supply to climate change, Nature Climate Change 2 (9) (2012) 676-681.

[12] M. D. Bartos, M. V. Chester, Impacts of climate change on electric power supply in the western united states, Nature Climate Change.

[13] B. Head, N. Cammerman, The Water-Energy Nexus: A Challenge for Knowledge and Policy, The University of Queensland, 2010.

[14] M. D. Bartos, M. V. Chester, The conservation nexus: Valuing interdependent water and energy savings in arizona, Environmental science \& technology 48 (4) (2014) 2139-2149.

[15] G. Klein, M. Krebs, V. Hall, T. OBrien, B. Blevins, Californias water-energy relationship, California Energy Commission.

[16] C. Maas, Ontario's Water-energy Nexus: Will We Find Ourselves in Hot Water-Or Tap Into Opportunity?, POLIS Project on Ecological Governance, 2010. 
[17] P. Linke, On the development of strategies for water and energy management in the context of the water-energy-food nexus, in: Proceedings of the 8th International Conference on Foundations of Computer-Aided Process Design, Vol. 34, Elsevier, 2014, p. 196.

[18] D. M. Marsh, The water-energy nexus: a comprehensive analysis in the context of new south wales, Ph.D. thesis, University of Technology, Sydney (2008).

[19] R. Pate, M. Hightower, C. Cameron, W. Einfeld, Overview of energy-water interdependencies and the emerging energy demands on water resources, Tech. rep., Report: SAND 2007-1349C (2007). URL http://www.circleofblue.org/waternews/wp-content/uploads/2010/09/SANDIA-research-needs2007-1349C_ revised.pdf

[20] D. Fang, B. Chen, Linkage analysis for the water-energy nexus of city, Applied Energy.

[21] G. Rasul, B. Sharma, The nexus approach to water-energy-food security: an option for adaptation to climate change, Climate Policy 16 (6) (2016) 682-702.

[22] R. Badiani, K. Jessoe, The impact of electricity subsidies on groundwater extraction and agricultural production, University of California at Davis, working Paper (2013). URL http://economics.ucdavis.edu/events/papers/Jessoe51.pdf

[23] M. Gulati, S. Pahuja, Direct delivery of power subsidy to manage energy-ground water-agriculture nexus, Aquatic Procedia 5 (2015) 22-30.

[24] J. R. Stokes, A. Horvath, Energy and air emission effects of water supply, Environmental science \& technology 43 (8) (2009) 2680-2687.

[25] S. C. Parkinson, N. Djilali, V. Krey, O. Fricko, N. Johnson, Z. Khan, K. Sedraoui, A. H. Almasoud, Impacts of groundwater constraints on saudi arabias low-carbon electricity supply strategy, Environmental science \& technology 50 (4) (2016) 1653-1662.

[26] A. S. Vieira, E. Ghisi, Water-energy nexus in low-income houses in brazil: the influence of integrated on-site water and sewage management strategies on the energy consumption of water and sewerage services, Journal of Cleaner Production 133 (2016) 145-162.

[27] Y. Gu, Y.-n. Dong, H. Wang, A. Keller, J. Xu, T. Chiramba, F. Li, Quantification of the water, energy and carbon footprints of wastewater treatment plants in china considering a water-energy nexus perspective, Ecological Indicators 60 (2016) 402-409.

[28] A. M. R. Carrillo, C. Frei, Water: A key resource in energy production, Energy Policy 37 (11) (2009) 4303-4312.

[29] M. Bazilian, H. Rogner, M. Howells, S. Hermann, D. Arent, D. Gielen, P. Steduto, A. Mueller, P. Komor, R. S. Tol, et al., Considering the energy, water and food nexus: Towards an integrated modelling approach, Energy Policy 39 (12) (2011) $7896-7906$.

[30] T. V. H. Le, H. N. Nguyen, E. Wolanski, T. C. Tran, S. Haruyama, The combined impact on the flooding in vietnam's mekong river delta of local man-made structures, sea level rise, and dams upstream in the river catchment, Estuarine, Coastal and Shelf Science 71 (1) (2007) 110-116.

[31] J. S. Mehta, The indus water treaty: a case study in the resolution of an international river basin conflict, in: Natural Resources Forum, Vol. 12, Wiley Online Library, 1988, pp. 69-77.

[32] SEI, Water evaluation and planning system (WEAP) Stockholm Environment Institute (SEI), accessed: 08 August 2016 (2016). URL http://www .weap21.org/index.asp

[33] D. P. Loucks, E. Van Beek, J. R. Stedinger, J. P. Dijkman, M. T. Villars, Water resources systems planning and management: an introduction to methods, models and applications, Paris: Unesco, 2005.

[34] A. Mayer, A. Muñoz-Hernandez, Integrated water resources optimization models: an assessment of a multidisciplinary tool for sustainable water resources management strategies, Geography Compass 3 (3) (2009) 1176-1195.

[35] K. Fedra, Water Resources Simulation and Optimization: A web based approach Environmental Software and Services, accessed: 11 October 2016 (2005). URL http://ftp.ess.co.at/OPTIMA/PUBS/fedra-aruba.pdf

[36] SEI, Long-range Energy Alternatives Planning System (LEAP) Stockholm Environment Institute (SEI), accessed: 08 August 2016 (2016).

URL https://www.energycommunity.org/default.asp?action=home

[37] Enerdata, Prospective Outlook on Long-term Energy Systems (POLES), Enerdata, accessed: 08 August 2016 (2016). URL http://www.enerdata.net/enerdatauk/solutions/energy-models/poles-model.php

[38] L. G. Fishbone, H. Abilock, Markal, a linear-programming model for energy systems analysis: Technical description of the bnl version, International journal of Energy research 5 (4) (1981) 353-375.

[39] R. Loulou, U. Remme, A. Kanudia, A. Lehtila, G. Goldstein, Documentation for the TIMES Model. Energy Technology Systems Analysis Programme (ETSAP) (2005).

URL http://www.iea-etsap.org/index.php/documentation

[40] IPCC, 2014, Climate Change 2014: Mitigation of Climate Change. Contribution of Working Group III to the Fifth Assessment Report of the Intergovernmental Panel on Climate Change Cambridge University Press, Cambridge, United Kingdom and New York, NY, USA, 2014. URL http://www.ipcc.ch/report/ar5/wg3/

[41] Z. Khan, P. Linares, J. García-González, Integrating water and energy models for policy driven applications. a review of contemporary work and recommendations for future developments, Renewable and Sustainable Energy Reviews 67 (2017) $1123-1138$.

[42] P. Faeth, B. K. Sovacool, Z. Thorkildsen, A. Rao, D. Purcell, J. Eidness, K. Johnson, B. Thompson, S. Imperiale, 
A. Gilbert, A Clash of Competing Necessities: Water Adequacy and Electric Reliability in China, India, France, and Texas, CNA Research Memorandum.

[43] S. Bouckaert, S. Selosse, E. Assoumou, A. Dubreuil, N. Maïzi, Analyzing water supply in future energy systems using the times integrating assessment model (tiam-fr), Journal of Systemics, Cybernetics and Informatics 10 (1) (2012) 89-94.

[44] S. Bouckaert, E. Assoumou, S. Selosse, N. Maïzi, A prospective analysis of waste heat management at power plants and water conservation issues using a global times model, Energy 68 (2014) 80-91.

[45] S. M. Cohen, J. Macknick, K. Averyt, J. Meldrum, Modeling climate-water impacts on electricity sector capacity expansion, in: ASME 2014 Power Conference, American Society of Mechanical Engineers, 2014, pp. V002T10A007-V002T10A007.

[46] A. Bhattacharya, B. K. Mitra, Water Availability for Sustainable Energy Policy: Assessing cases in South and South East Asia. IGES Research Report 2013-01, Tech. rep. (2013).

URL http://pub.iges.or.jp/modules/envirolib/upload/4836/attach/IGES_Research__Report_2013-01_Water_ energy_nexus.pdf

[47] V. Bhatt, K. M. Crosson, W. Horak, A. Reisman, New York city energy water integrated planning: A pilot study (BNL81906-2008), Tech. rep., Brookhaven National Laboratory (BNL) (2008).

[48] M. Welsch, S. Hermann, M. Howells, H. H. Rogner, C. Young, I. Ramma, M. Bazilian, G. Fischer, T. Alfstad, D. Gielen, et al., Adding value with CLEWS-Modelling the energy system and its interdependencies for Mauritius, Applied energy 113 (2014) 1434-1445.

[49] S. C. Parkinson, M. Makowski, V. Krey, K. Sedraoui, A. H. Almasoud, N. Djilali, A multi-criteria model analysis framework for assessing integrated water-energy system transformation pathways, Applied Energy.

[50] E. G. Davies, P. Kyle, J. A. Edmonds, An integrated assessment of global and regional water demands for electricity generation to 2095, Advances in Water Resources 52 (2013) 296-313.

[51] M. Hejazi, J. Edmonds, L. Clarke, P. Kyle, E. Davies, V. Chaturvedi, M. Wise, P. Patel, J. Eom, K. Calvin, et al., Long-term global water projections using six socioeconomic scenarios in an integrated assessment modeling framework, Technological Forecasting and Social Change 81 (2014) 205-226.

[52] D. Marsh, D. Sharma, A framework for assessing integrated water and energy management scenarios, 2007.

[53] D. Perrone, J. Murphy, G. M. Hornberger, Gaining perspective on the water- energy nexus at the community scale, Environmental science \& technology 45 (10) (2011) 4228-4234.

[54] W. N. Lubega, A. M. Farid, Quantitative engineering systems modeling and analysis of the energy-water nexus, Applied Energy 135 (2014) 142-157.

[55] M. Howells, S. Hermann, M. Welsch, M. Bazilian, R. Segerström, T. Alfstad, D. Gielen, H. Rogner, G. Fischer, H. van Velthuizen, et al., Integrated analysis of climate change, land-use, energy and water strategies, Nature Climate Change 3 (7) (2013) 621-626.

[56] I. Kraucunas, L. Clarke, J. Dirks, J. Hathaway, M. Hejazi, K. Hibbard, M. Huang, C. Jin, M. Kintner-Meyer, K. K. van Dam, et al., Investigating the nexus of climate, energy, water, and land at decision-relevant scales: the platform for regional integrated modeling and analysis (prima), Climatic Change 129 (3-4) (2014) 573-588.

[57] P. I. Helgesen, Top-down and Bottom-up:Combining energy system models and macroeconomic general equilibrium models, Center for Sustainable Energy Studies (CenSES), cenSES workng paper 1/2013 (2013). URL https://www.ntnu.no/documents/7414984/202064323/2013-12-11+Linking+models_444.pdf/ 4252b320-d68d-43df-81b8-e8c72ea1bfe1

[58] A. Krook-Riekkola, C. Berg, E. O. Ahlgren, P. Söderholm, Challenges in Soft-Linking: The Case of EMEC and TIMESSweden (2013)

[59] C. Böhringer, T. F. Rutherford, Integrated assessment of energy policies: Decomposing top-down and bottom-up, Journal of Economic Dynamics and Control 33 (9) (2009) 1648-1661.

[60] P. Linares, C. Romero, A multiple criteria decision making approach for electricity planning in spain: economic versus environmental objectives, Journal of the Operational Research Society 51 (6) (2000) 736-743.

[61] P. Linares, C. Romero, Aggregation of preferences in an environmental economics context: a goal-programming approach, Omega 30 (2) (2002) 89-95.

[62] A. Brooke, D. Kendrick, A. Meeraus, R. Raman, The general algebraic modeling system, GAMS Development Corporation.

[63] T. Asano, F. Burton, H. Leverenz, R. Tsuchihashi, G. Tchobanoglous, Water reuse: Issues, technologies, and applications, McGrawHill, New York, USA.

[64] S. Grin, Geometry and area-depth-volume curves of the reservoirs in the semiarid madalena basin in northeast brazil final Bachelor Report.

URL http://essay.utwente.nl/66590/1/Grin_Sido.pdf

[65] J. Coleman, The effect of ambient air and water temperature on power plant efficiency. Nicholas School of the Environment and Earth Sciences, Duke University, master's Project (2013). URL http://hdl.handle.net/10161/6895

[66] Álvaro López-Peña, Evaluation and design of sustainable energy policies. an application to the case of spain, Ph.D. thesis, Universidad Pontificia Comillas de Madrid, Madrid, Spain (2014).

[67] Á. López-Peña, I. Pérez-Arriaga, P. Linares, Renewables vs. energy efficiency: The cost of carbon emissions reduction in spain, Energy Policy 50 (2012) 659-668.

[68] D. J. Rodriguez, Quantifying the tradeoffs of the water energy nexus, World Bank, World Water Week 2013, Stockholm, 2013.

URL http://www.wsp.org/sites/wsp.org/files/publications/Water-and-Energy-World-Bank-SIWI2013.pdf

[69] Z. Khan, P. Linares, J. García-González, Adaptation to climate-induced regional water constraints in the spanish energy sector: An integrated assessment, Energy Policy 97 (2016) 123-135. 
[70] R. I. Esteban, E. O. de Miguel, Present and future of wastewater reuse in spain, Desalination 218 (1) (2008) 105-119.

[71] N. Hernández-Mora, L. del Moral Ituarte, F. La-Roca, A. La Calle, G. Schmidt, Interbasin water transfers in spain: Interregional conflicts and governance responses, in: Globalized Water, Springer, 2014, pp. 175-194.

[72] L. Hardy, A. Garrido, L. J. Sirgado, Análisis y evaluación de las relaciones entre el agua y la energía en España, Fundación Marcelino Botín Santander, Spain, 2010.

[73] British Petroleum (BP) chair on energy and sustainability in Spain, Spanish energy sankey, British Petroleum (BP) Spain and Comillas Pontifical University, accessed: 08 August 2016 (2016). URL http://web.upcomillas .es/centros/bp/D3_Sankey/sankey_energy.html

[74] Ministerio de medio ambiente, Gobierno de España, Libro blanco del agua en España, Secretaría de estado de aguas y costas, Madrid, Spain, 2000.

[75] Ministerio de medio ambiente, Gobierno de España, Ministerio de medio ambiente, sistema integrado de información del agua, http://servicios2.magrama.es/sia/visualizacion/descargas/capas.jsp\#EMBALSE accessed: 2014-02-09 (2013).

[76] Comisi'on Nacional de Energía, Régimen especial de producción de energía eléctrica en españa, Tech. rep., Informe mensual de ventas de energía del régimen especial (2013).

[77] Centro de Estudios y Experimentación de Obras Públicas (CEDEX), Estudio de los impactos del cambio climático en los recursos hídricos y las masas de agua, effecto del cambio climático en los recursos hídricos disponibles en los sistemas de explotación, centro de Estudios Hidrográficos, CEDEX: 43-308-5-001 (2012).

[78] Red Eléctrica de España, Publications: Statistical series, http://www.ree.es/en/publications/ indicators-and-statistical-data/statistical-series, accessed: 2016-03-09.

[79] Ministerio de Agricultura, Alimentación y Medio Ambiente, Gobierno de España, Planes hidrológicos de cuenca vigentes web Page, Accessed: 2016-03-21.

URL http://www.mag planes-cuenca/default.aspx

[80] Ministerio de medio ambiente, Gobierno de España, Precipitation, accessed: 2016-02-08. URL http://servicios2.magrama.es/sia/visualizacion/descargas/series.jsp\#PRECIPITACION

[81] Ministerio de medio ambiente, Gobierno de España, Libro blanco digital del agua en españa: Recursos no convenciales, reutilizacion accessed: 2016-03-08 (2008).

URL http://servicios2.marm.es/sia/visualizacion/lda/recursos/noconvencionales_reutilizacion.jsp

[82] The shift project (TSP), Historical energy consumption statistics The Shift Project Data Portal, accessed: 08 August $2016(2016)$. URL http://www.tsp-data-portal.org/Energy-Consumption-Statistics\#tspQvChart

[83] L. Hardy, A. Garrido, L. Juana, Evaluation of spain's water-energy nexus, International Journal of Water Resources Development 28 (1) (2012) 151-170.

[84] United States Energy Information Administration (US EIA), International energy statistics, US-EIA, accessed: 08 August $2016(2016)$.

URL https://www.eia.gov/beta/international/data/browser/\#/?c=00000000000004\&ct=0\&vo=0\&v=H\&start=1980\&end= 2014\&showdm=y 